\title{
Experiences and Perceptions of West Virginia Stakeholders towards Industrial Hemp and its End Uses
}

\author{
Rebekah K. Stevenson
}

Follow this and additional works at: https://researchrepository.wvu.edu/etd

\section{Recommended Citation}

Stevenson, Rebekah K., "Experiences and Perceptions of West Virginia Stakeholders towards Industrial Hemp and its End Uses" (2017). Graduate Theses, Dissertations, and Problem Reports. 6727.

https://researchrepository.wvu.edu/etd/6727

This Thesis is protected by copyright and/or related rights. It has been brought to you by the The Research Repository @ WVU with permission from the rights-holder(s). You are free to use this Thesis in any way that is permitted by the copyright and related rights legislation that applies to your use. For other uses you must obtain permission from the rights-holder(s) directly, unless additional rights are indicated by a Creative Commons license in the record and/ or on the work itself. This Thesis has been accepted for inclusion in WVU Graduate Theses, Dissertations, and Problem Reports collection by an authorized administrator of The Research Repository @ WVU. For more information, please contact researchrepository@mail.wvu.edu. 
Experiences and Perceptions of West Virginia Stakeholders towards Industrial Hemp and its End Uses

Rebekah K. Stevenson

Thesis submitted to the

Davis College of Agriculture, Natural Resources and Design

at West Virginia University

in partial fulfillment of the requirements

for the degree of

\author{
Master of Science \\ in \\ Design and Merchandising \\ Katie Jones, Ph. D. Chair \\ Chris Haddox, Ph. D. \\ Beth Newcome, Ph. D
}

School of Design and Community Development

Morgantown, West Virginia

2017

Keywords: Hemp, West Virginia, Experiences, Perceptions, Stakeholders

Copyright 2017 Rebekah K. Stevenson 


\begin{abstract}
Experiences and Perceptions of West Virginia Stakeholders towards Industrial Hemp and its End Uses

Rebekah K. Stevenson

Industrial hemp is an herbaceous, annual plant from the cannabis sativa family. It is highly desirable due to its end uses, adaptability to climates for farming, ease of growth, and overall profitability. Its versatile nature provides a valuable source of raw materials for fibers, oil, seed, and food. A renewable fiber, industrial hemp returns nitrogen into the soil after it the plant has been harvested and plowed into the field. The crop was mistakenly placed on Schedule 1 of the Controlled Substances list in the 1970s due to its species relation to marijuana. Industrial hemp has been restricted until several years ago when states, including West Virginia, allowed it to be grown for research, commercial, and pilot programs. West Virginia, a state coping with unemployment and needing an economic boost, has since approved industrial hemp and planted its first crop in 2016. The purpose of this study is to explore the experiences and perceptions of West Virginia industrial hemp stakeholders. To better understand these experiences, semistructured interviews were coupled with a mind map. Participants were gathered through snowball sampling from the West Virginia Farmer's Cooperative. The study provides a source of information to new growers, educators, politicians and others advocating or curious about attitudes and experiences towards industrial hemp in West Virginia. Of interest, may be the barriers to hemp's expansion in the West Virginia context that emerged from this study.
\end{abstract}




\section{TABLE OF CONTENTS}

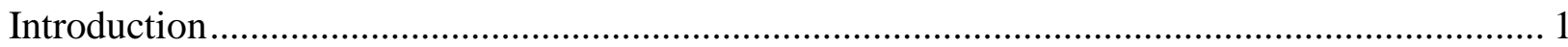

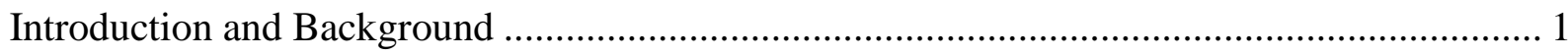

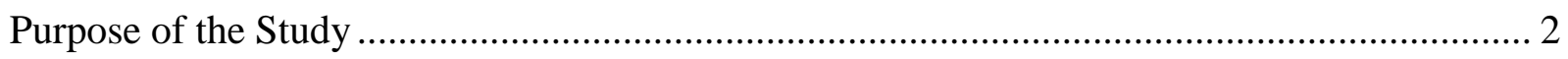

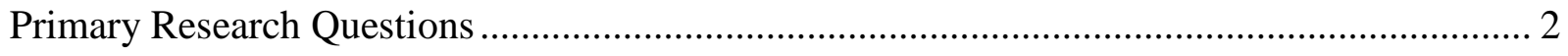

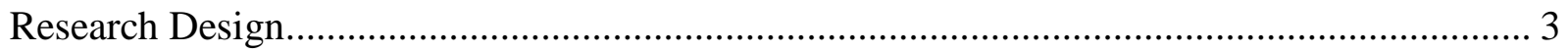

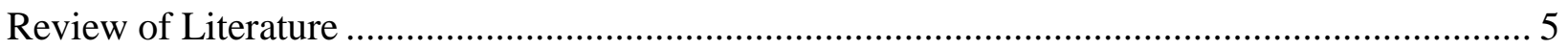

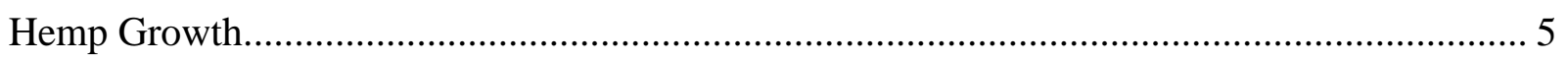

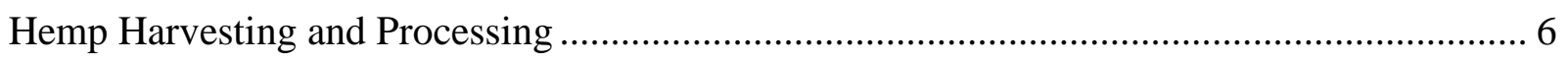

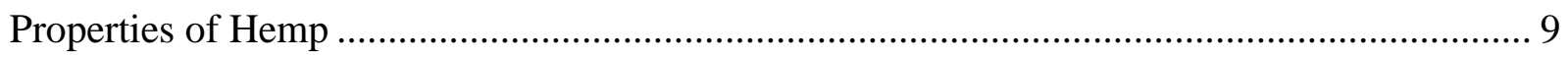

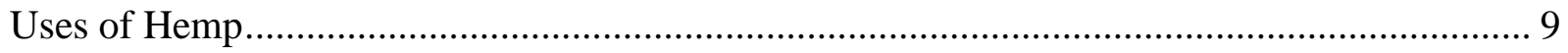

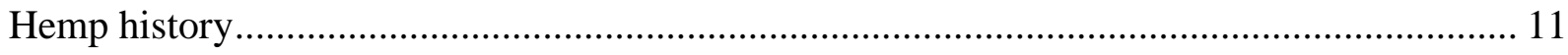

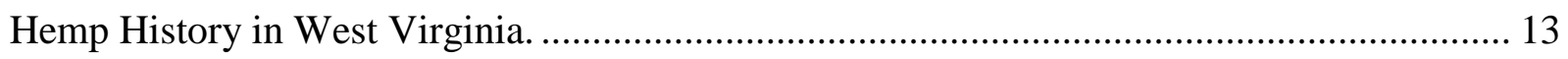

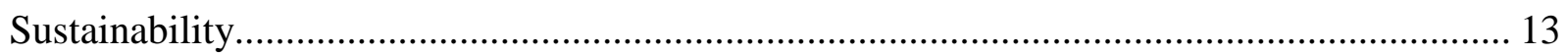

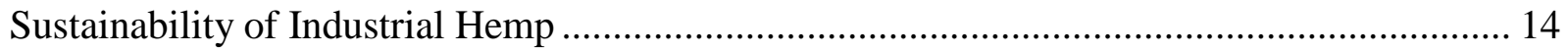

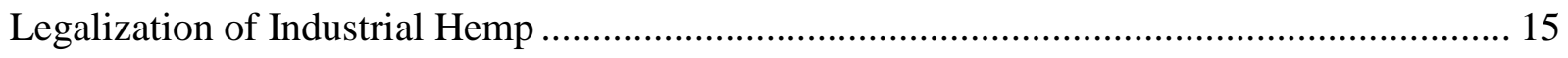

Legalization of Industrial Hemp in West Virginia. ............................................................. 17

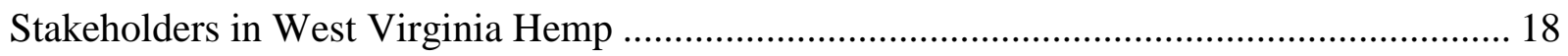

Future Opportunities in Research......................................................... 19

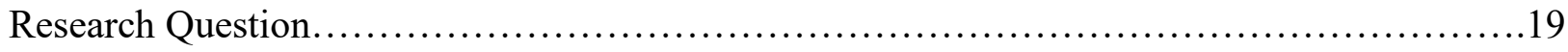


Phenomenology

Lived experience.

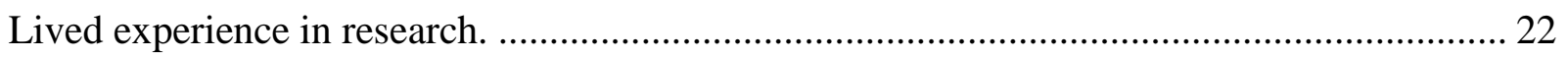

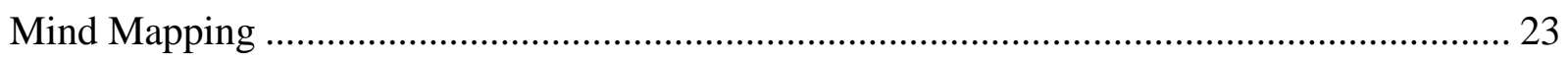

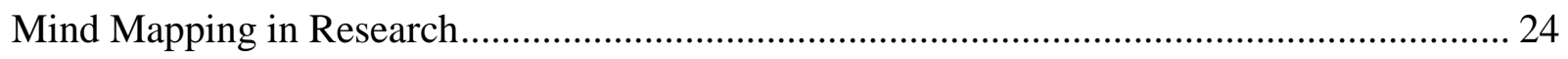

Appropriateness of Research Methods …………………................................................ 25

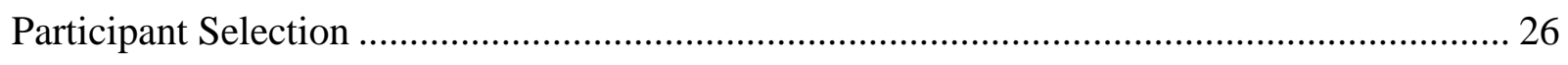

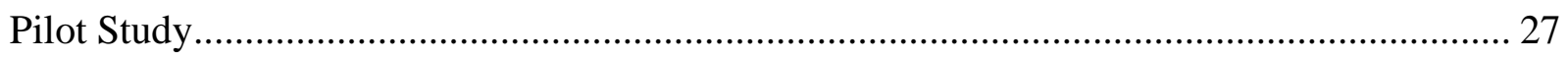

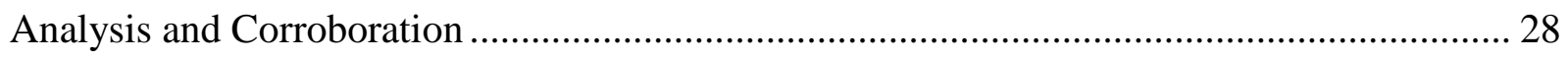

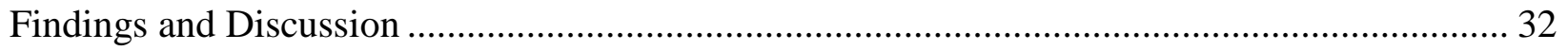

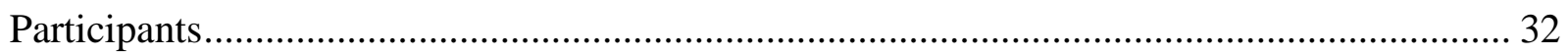

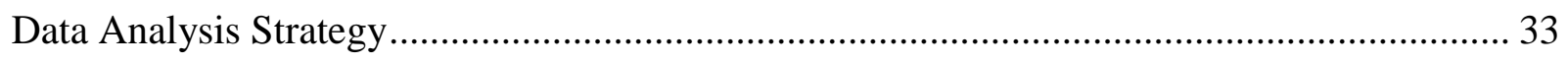

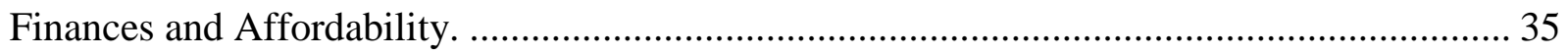

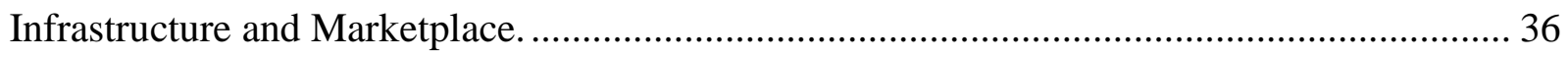

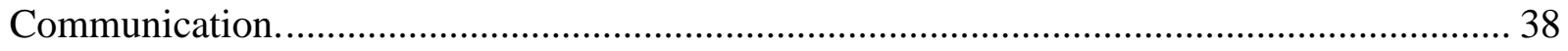

Latent and Extended Knowledge..................................................................................... 39

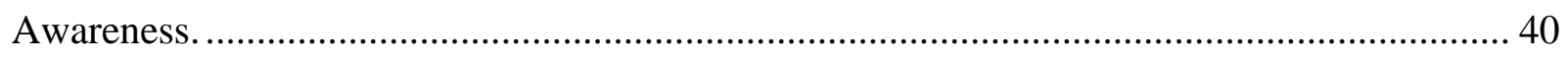

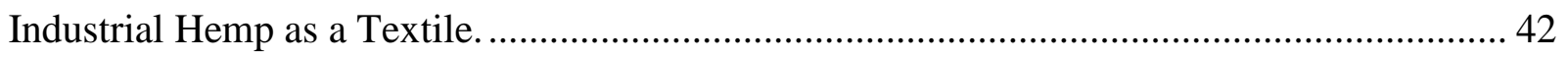

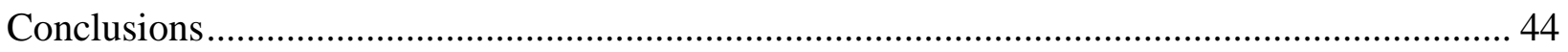


Outcomes and Implications

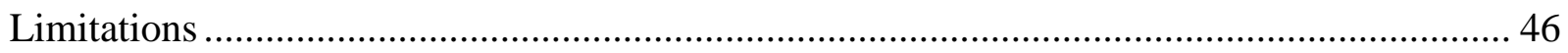

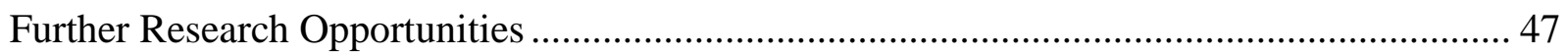

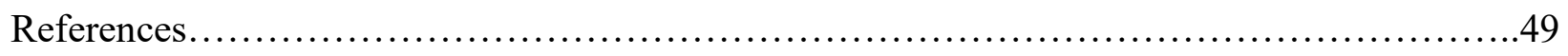

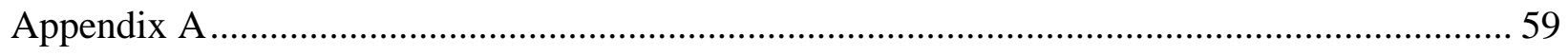

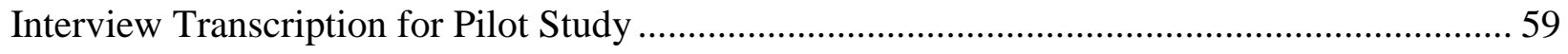

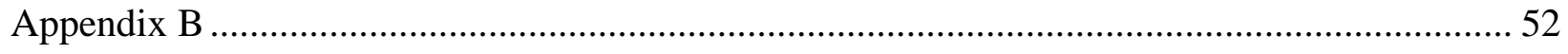

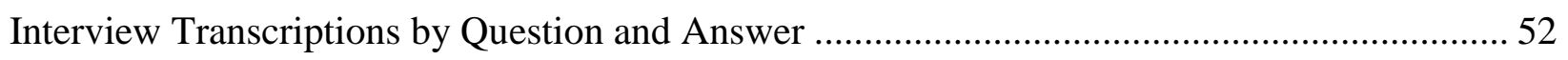

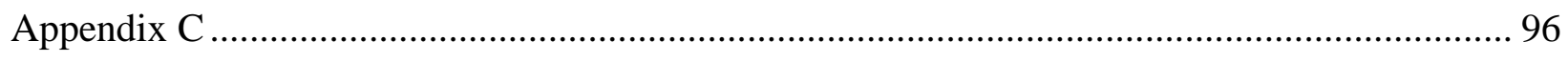

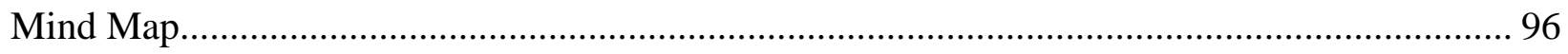

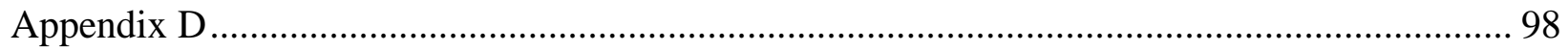

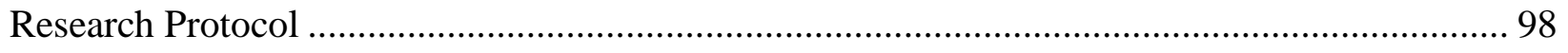


List of Tables

Table 1 Uses of Industrial Hemp with their Properties or Benefits, Classifications or

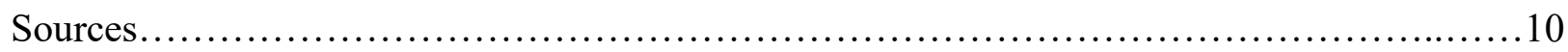

Table 2 Summary of Interview Questions and Categories................................................30

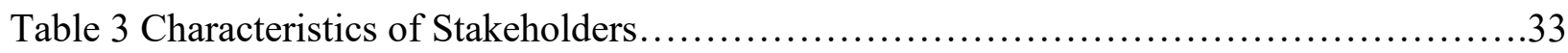

Table 4 Themes and Supporting Responses........................................44 


\section{CHAPTER I}

\section{Introduction}

\section{Introduction and Background}

Industrial hemp is often referred to as the billion-dollar crop because of its wide variety of end uses, adaptability to climates for farming, ease of growth, and its overall profitability (Johnson, 2011). As a natural fiber, it possesses all the properties that are desirable in durability, strength, high absorbency, anti-mold/microbial, etc. (Kadaloph, 2010). These properties make any fiber naturally desirable for their comfort level and the ability to modify those properties that may not be appealing. This overall benefit of ease and usability makes industrial hemp a crop that is desired to be cultivated and processed in the United States (USDA, 2000). Industrial hemp has abundant end uses. Its potential can be found in construction materials, textiles, paper, plastic, food, medicinal purposes, cosmetics, and much more.

However, the accessibility to the crop and prolific growth is not the case and since 1958, industrial hemp's growth has been made stagnant for a variety of reasons unrelated to its desirability (Allegret, 2013). Industrial hemp has not been prolifically grown in the U.S. after it was placed on the Controlled Substances Act's list due to misinformation on its THC (tetrahydrocannabinol) content. Though profitable, industrial hemp faces some major challenges and scrutiny not only from its THC associations, but limited access to the crop for cultivation, processing, and marketing. The scrutiny is, per reports and research, unfounded, but changes are slow in coming.

Because of the gap in the years that industrial hemp has not been grown, processing plants for industrial hemp are severely limited to states like North Carolina or even out of the country into Canada. Exporting the crop to either location that is not close in proximity is costly 
and not easily accessible. Currently, industrial hemp is permitted to be grown in several states under different sanctions. In West Virginia, industrial hemp may be grown for research, commercial, and pilot purposes (West Virginia Legislature, 2016). Because of industrial hemp's gap in the literature review and its profitability for West Virginia, this research will seek to explore the experiences, perceptions, and attitudes that stakeholders in industrial hemp within West Virginia have about this crop and its end uses.

\section{Purpose of the Study}

The purpose of this study is to explore the experiences and perceptions that stake holders in West Virginia have towards industrial hemp. The study also examines their attitudes and associations with the end uses of industrial hemp, specifically as a material for textiles. The study explored how these stakeholders are coping with the process of being involved in industrial hemp whether in a retail business, growing it for research purposes, making it into a product, or even advocating for it legally.

Having the opportunity to delve into this study of the stakeholder's experiences is unique in that it allows future industrial hemp activists to see how those who have preceded them have functioned. Not only that, but will also include information on how to cope with industrial hemp as it struggles to gain legalization. Firsthand accounts are compelling as they give an inside look at a person's life. This study endeavors to do the same by providing a piece of that look at West Virginia stakeholders.

\section{Primary Research Questions}

The research is targeting those who are involved in industrial hemp in any capacity, those who are interested in pursuing an interest in this crop, and those who are interested in any of the aspects of industrial hemp's uses, properties, growth, or processing. Because there is little 
information from each state that is currently growing industrial hemp, this research contributes to the existing body of knowledge with research from West Virginia specifically. The research is also significant in that while most research is quantitative in this field-statistical studies on its profit or frequencies of origins of growth - this research is qualitative looking at the lived experiences of the participants. This research is their stories and lives of how they perceive this crop. It traces their background interest, networks, involvement, and other functions that they go through regularly. These functions are performed while actively pursuing industrial hemp as a means of support, hobby, or other capacity.

The primary research question studies the culture surrounding those who are actively engaged in industrial hemp. What are the attitudes, experiences, and perceptions of West Virginia stakeholders towards industrial hemp and its end uses? While some research is being conducted about industrial hemp in West Virginia, there is no research currently studying that culture. The lived experience of the individual is important in understanding how this specific crop is being perceived. The importance lies in industrial hemp as a crop increasingly becoming noticed and legalized in different states. If West Virginia is to become one of these states that taking of this crop's many benefits, there must be supporting literature to show those interested how it works and the personal lives of those involved. Many people want to know how others have fared in a certain situation before they get into it. The same is applicable for industrial hemp. If an individual wants to be involved in the crop, they will most likely start researching and want to know what the experiences have been of others that have been involved before them.

\section{Research Design}

This research has met the exemption of the Institutional Review Board \#1609297023. Based on a phenomenological, lived experience research design, it used semi-structured 
interviews and mind mapping. The participants in the research were stakeholders in industrial hemp in West Virginia. Stakeholders are defined as those persons who are actively involved in any aspect of industrial hemp, whether in farming, retail, political, or other. The participants were gathered through snow-ball sampling where each new participant referred the researcher to another possible participant. For this study, a participant was contacted using the West Virginia Hemp Farmer's Cooperative. This contact then referred the researcher on to other possible participants. There are few options of those to interview as well as those who are possible participants are often difficult to find due to their smaller scale operations, their information is not easily attainable through other means.

The interviews consisted of semi-structured questions that were divided into categories; knowledge base, involvement and support, future of industrial hemp in West Virginia, and industrial hemp as textile. The questions are structured as open ended questions that the participant can answer from any type of active work they are pursuing in this crop. The interviews took approximately 30-45 minutes, excluding the time the participants puts into the mind map. After transcription, the documents were read and examined to check for developing themes across the transcripts. 


\section{CHAPTER II \\ Review of Literature}

\section{Hemp Growth}

Hemp is a herbaceous annual plant that grows quickly in temperate climates and can survive in altitudes up to 8,000 feet (Joseph, 1986). It is a variation of the Cannabis sativa family. Atypically from common belief about the differences between male and female plants, male hemp plants are called fimble hemp because they are shorter and thinner, while female plants are called carl hemp since they are taller and fuller (Wilson, 1979). Fimble plants are picked for their fibers, while the carl plants are selected for both their fiber and seed properties (Wilson, 1979). The hemp plants will reach heights between 10-14 feet in about three months (Humphries, 2004; Ash, 1948). The plants require substantial nutrients, adequate moisture, and grow well in areas where corn production is proficient (USDA, 2011; Ash, 1948).

Industrial hemp is hemp that is grown only as a fiber or seed crop for textiles, paper, construction materials, or composites and contains less than $1 \%$ of tetrahydrocannabinol (THC) (USDA, 2000; Fortenberry \& Bennett, 2003). Its cultivation is an organized process for mass production of serviceable products focusing on fiber and oil production (Bouloc, 2013a; Allegret, 2013). When industrial hemp is grown as a fiber, the plants are grown in a broadcast culture seeds scattered in no order - with ideal stalks that are three to 10 feet tall (ideally six feet) and one sixth to five sixths inches in diameter (USDA, 2011; Ash, 1948). Industrial hemp plants that are grown for seed products are grown in checks or drills - seeds are planted in orderly rows which enables them to spread and typically have a height between 12 to 16 feet and a diameter of two fifths to two inches (USDA, 2011). 
The leaves are palmately compound and can have seven to 11 leaflets with a serrate margin (Ash, 1948). Hemp flowers are small, yellowish-green, and are subtle with fimble plants producing more flowers than the carl plants (Woodhouse \& Kilgour, 1919). When preparing the land for a hemp crop, it must be thoroughly plowed and repeatedly harrowed to make as fine and uniform a seedbed as possible (Ash, 1948). The seed for the hemp can be sowed either by hand or by machine depending on the resources of the planter and the size and placement of the field. Typically, the seed is planted with one bushel or 44 pounds of hemp seed per acre (Ash, 1948). Once sown, the seed is lightly covered with an inch of dirt and 95 percent of the seed will germinate (USDA, 2011). Hemp will cover the ground quickly and smother any weeds which eliminates the need for an herbicide (Bouloc \& van der Werf, 2013). Studies in France have shown that few diseases cause significant damage to an industrial hemp crop because of their ability to reach the nutrients they need and ability to cope with their environment (Bouloc \& van der Werh, 2013).

\section{Hemp Harvesting and Processing}

Hemp plants are sensitive to day length and mature as the days get shorter in the fall (USDA, 2011). The plants are ready for harvest in about three or four months, depending on their seed strain and whether they are a carl or fimble plant (Ash, 1948). Fimble plants are harvested first when the flowers reach maturity and when the leaves have changed from green to brown in color (Woodhouse \& Kilgour, 1919). Carl plants are shorter and harvested when the seeds just begin to ripen. Both carl and fimble crops can be harvested together in a dual harvest, but the plants are usually not at the height of their production and are then typically used in products - such as pulp and paper - that do not require higher quality hemp as they are of lower value (USDA, 2011). Each acre that has been harvested for industrial hemp can produce up to six 
to seven centum weight (ctw), or two to five tons per acre (Woodhouse \& Kilgour, 1919; SmithHeisters, 2008).

Harvesting the hemp crop takes place in six steps: chemical defoliation, cutting, retting, baling, loading, and transporting. These processes are primarily to decrease the weight of the plants and discard unwanted foliage or intruding matter (Woodhouse \& Kilgour, 1919). The plants are cut and retting - the technical term for rotting - can come in the form of water retting or field retting (Fortenberry \& Bennett, 2003). Retting is an important process as it can determine the quality of the final product. Proper retting must be done so that the stalks do not receive too much moisture and rot completely, yet have enough to finish the rotting process that will break the stalks down (Ash, 1948). Water retting requires that the cut hemp plants - devoid of their leaves by the chemical defoliation - are bundled together with machinery that is designed to preserve the parallel alignment of the stalks (USDA, 2011). The stalks are then submerged in water where the natural rotting process breaks down the stalks for further processing. Water retting can produce a much finer product, but has higher financial and labor cost (Fortenberry \& Bennett, 2003). Field retting leaves the cut hemp stalks lying in the field for two to three week where, by natural process of dew and exposure, they will naturally rot in the field and then be collected for further processing. This type is less financial and labor intensive, but does not produce a higher grade of product (USDA, 2011).

Although both water and field retting have costs associated with them, there is also the factor of the country where the hemp is processed. In China and Hungary, where labor costs are low and environmental concerns less strict, water retting is commonly done in place of field retting. Several other countries are currently working on ways to reduce environmental and labor concerns so that they can practice water retting more frequently (USDA, 2000). In countries, 
such as, Italy, Yugoslavia, and Russia, the water retting is completed by simply submerging the stalks in a running stream with no chemical additives (Ash, 1948). Adding the chemicals will thoroughly and quickly rid the stalks of the leaves and break them down, but there is little to no environmental concern in merely using a stream.

After the fibers have been retted, the stalks are then sent to a processing mill for decortication and scutching. Decortication separates the dried stem's woody core -known as its hurds - into short pieces loosening the bast fibers from the hurds (Fortenberry \& Bennett, 2003). The scutching process separates the loosened fibers from the hurds and then is hackled separated into finer strands by being drawn over a series of fine pointed pins (Ash, 1948). After they are bundled together, the fibers can be sent on for further cleaning and processing into the desired finished product (USDA, 2011). Fibers from industrial hemp are graded and analyzed based upon three categories; purity in its proportion, color of the fiber, and the position of the fibers (Bouloc, 2013a). Purity is defined as the proportion of hurds to fibers. Hemp used for industrial purposes must have a purity level of hurds/fiber $\leq 2 \%$, paper production can have as high a percentage of $35 \%$, while hemp used for textiles must have as close $0 \%$ as possible (Bouloc, 2013a). The position of the fibers is desirable for textiles since the fibers are at their highest quality when they are aligned parallel to each other. In production as paper or pulp products, their parallelism is not as important as their homogeneity (Bouloc, 2013b). Although color is not as important as the other two categories because the finished textile can be altered with dyes or finishes, the preferred color of the fibers is white or blonde or, at least, a very light color (Bouloc, 2013b). 


\section{Properties of Hemp}

The plant is desired for its long, fibrous, strong stems which make it an appropriate source for many products. Hemp has many properties that make it desirable; it is resistant to bugs, has high absorbency, high tenacity, and good comfort (Kadolph, 2010). Industrial hemp is similar to flax and it can be difficult to tell the two apart in a macro and microscopic analysis. However, industrial hemp is coarser and stiffer than flax; traits that can be minimized with proper processing (Kadolph, 2010). The plant produces three different kinds of bast fibers; the outer region fibers, inner fibers, and the innermost fibers. Fiber from the outer region are typically the longest and finest, while the inner fibers are shorter and innermost are much more of a woody substance (Kadolph, 2010).

\section{Uses of Hemp}

As an industrial fiber, hemp contains a low profile of tetrahydrocannabinol (THC) and cannabidol (CDB) and can only be used profitably for the manufacture of textiles, construction materials, food, cosmetics, and other products requiring those properties related to industrial hemp (see Table 1) (Johnson, 2011). Known for its strength, industrial hemp is suitable for many products based upon the classification of the fiber as an outer, inner, or innermost fiber. 
Table 1

Uses of Industrial Hemp with their Properties or Benefits, Classifications or Sources

\begin{tabular}{|c|c|c|}
\hline Products & Properties and Benefits & Classification or Source \\
\hline \multirow[t]{2}{*}{ Food } & $\begin{array}{l}80 \% \text { EFA requirements, high } \\
\text { protein oils, cardiac benefits. }\end{array}$ & \multirow[t]{2}{*}{ Oil and seeds. } \\
\hline & $\begin{array}{l}\text { Renewable source of energy, } \\
\text { less reliance on fossil fuels. }\end{array}$ & \\
\hline \multirow{3}{*}{ Fuel } & One acre yields 1,000 gallons & \multirow{3}{*}{$\begin{array}{l}\text { Waste products from } \\
\text { processed hemp oil. }\end{array}$} \\
\hline & High tenacity and strong & \\
\hline & $\begin{array}{l}\text { mildew, mold, rotting, } \\
\text { ultraviolet, and abrasion, }\end{array}$ & \\
\hline \multirow[t]{2}{*}{ Textiles } & $\begin{array}{l}\text { resistance. Low chemical } \\
\text { residue. }\end{array}$ & \multirow[t]{2}{*}{$\begin{array}{l}\text { Inner and outermost fibers } \\
\text { from the stalk. }\end{array}$} \\
\hline & $\begin{array}{l}\text { Forest conservation, speed in } \\
\text { growth, high thermal }\end{array}$ & \\
\hline $\begin{array}{l}\text { Construction and } \\
\text { Landscaping materials }\end{array}$ & $\begin{array}{l}\text { insulation, less waste, } \\
\text { stronger and lighter than } \\
\text { wood. }\end{array}$ & \multirow[t]{2}{*}{$\begin{array}{l}\text { Entire stalk of the hemp plant } \\
\text { can be used. }\end{array}$} \\
\hline & $\begin{array}{l}\text { Lighter, stronger, and more } \\
\text { recyclable than other }\end{array}$ & \\
\hline Automobiles & $\begin{array}{l}\text { materials. Good sound and } \\
\text { shock absorption. } \\
\text { High nutritious value, more } \\
\text { quantity due to relatively }\end{array}$ & Stalk from the plant. \\
\hline \multirow[t]{2}{*}{ Livestock feed } & short growth process. & Hemp hurds. \\
\hline & $\begin{array}{l}\text { Can be molded into virtually } \\
\text { any shape, durable, less } \\
\text { residue from production, }\end{array}$ & $\begin{array}{l}\text { Cellulose remaining in the } \\
\text { stems after removal of the }\end{array}$ \\
\hline \multirow[t]{2}{*}{ Plastics } & lightweight, recyclable, and & \multirow[t]{2}{*}{ fibers. } \\
\hline & $\begin{array}{l}\text { High levels of Vitamins } \mathrm{A}, \mathrm{C} \text {, } \\
\text { and } \mathrm{E} \text {, rich in amino acids, } \\
\text { and antioxidants. Can prevent } \\
\text { moisture loss and restore skin }\end{array}$ & \\
\hline \multirow{4}{*}{$\begin{array}{l}\text { Cosmetics } \\
\text { Paper }\end{array}$} & lipids. & \multirow[t]{3}{*}{ Oil crushed from seeds. } \\
\hline & High cellulosic content, low & \\
\hline & $\begin{array}{l}\text { lignin content, durability, and } \\
\text { is biodegradable. Paper does }\end{array}$ & \\
\hline & $\begin{array}{l}\text { not lose color after many } \\
\text { years. }\end{array}$ & $\begin{array}{l}\text { Outermost fibers from the } \\
\text { stalk. }\end{array}$ \\
\hline
\end{tabular}

As an additional benefit, it has an increased efficacy and reduced use of herbicides and

pesticides. There are some environmental concerns with using hemp for specialized textiles, 
mainly the annual disruption of the soil to plant the crops thereby causing higher disturbance of wildlife and other biological principles (Smith-Heisters, 2008).

\section{Hemp history}

Hemp is a natural, cellulosic, bast fiber from the Mulberry family Moraceae, genus Cannabis sativa L., a family that is represented in at least 22 varieties of the fiber crop. This family includes: Manila (abaca), sisal, sunn, New Zealand, Mauritius, bowstring, Russian, Italian, and Indian hemp (Small \& Marcus, 2002; Humphries, 2004; Woodhouse \& Kilgour, 1919). Although the exact date is disputed, hemp is generally believed to have been first cultivated for industrial use around 6 millennia ago in areas of China's Yunnan province and in areas of Egypt as a fiber cultigen (Bouloc, 2013a; Woodhouse \& Kilgour, 1919). Hemp is referred to as a camp follower because of its ability to adapt and grow as humans migrate. The Greek historian, Herodotus, recorded hemp in his accounts of the Thracians. There is evidence of its present cultivation in that same area (Woodhouse \& Kilgour, 1919). Pliny, Roman author, naturalist, and philosopher, is also known to have recorded the growth and uses of hemp. His accounts are later than Herodotus' and seem to indicate a more efficient and refined production and processing of the fibers (Woodhouse \& Kilgour, 1919). A palynology examination of archaeological samples dates hemp's arrival in Europe at about $3450 \mathrm{BC}$ in northern Italy and central and northern Germany. Amounts of hemp pollen have also been in Scandinavia, France, and England between 2900 and 1700 BC (Allegret, 2013).

In North America, hemp was brought in force to the colonies by the Puritans around 1645 as a crop to be grown for fiber (Fortenberry \& Bennett, 2003). According to Wilson (1979), however, the Native Americans were using hemp prior to colonization of New England as cordage and nets. Thus, it is possible that the Puritans served as an increase to its production and 
not the propagator of the plant. Its cultivation spread primarily to Kentucky, Missouri, Illinois, and Virginia during the 1700s, but never rivaled flax in demand (USDA, 2011). Virginia was known for a finer grade of hemp that was suitable for apparel and linens while the other states used their hemp for cordage, nets, and rope (Wilson, 1979). Fortenberry and Bennett (2003) say the paper on which the Declaration of Independence was written was made from hemp and was also used in the construction of clothing for soldiers during the Revolutionary War. The first pair of Levis was also made from hemp, giving it an important history in American textiles. During the Industrial Revolution, the use of hemp began to decline with the advent of new sources of energy or materials that began to overshadow the use of hemp (Allegret, 2013). The advent of Eli Whitney's cotton gin meant that cotton was also more accessible and soon overshadowed hemp because of its rapid processing.

Because of its perceived connection to marijuana, hemp was put under regulatory control through the 1937 Marijuana Tax Act (Johnson, 2011). Its growth further diminished after this Tax Act as farmers wanted crops that would not require permits to grow (USDA, 2011) However, during World War II, hemp was used as a domestic substitute for abaca and jute which were unavailable for import due to the war (USDA, 2011). Since about 1958, hemp production in the United States has been negligible with a small industry in Wisconsin and Kentucky for textile purposes (Fortenberry \& Bennett, 2003). However, hemp has still been grown on almost every continent and in every country (Hess, 1958). By 1958, Poland, Russia, Yugoslavia, and Romania were producing hemp domestically, but were not exporting a large amount to other nations (Hess, 1958). Currently, hemp has renewed research interest as an economic source, its positive implications on sustainability, ethics of hemp production, and value of adjustability to other climates (Johnson, 2011). 


\section{Hemp History in West Virginia.}

Although there is extensive literature on the history of hemp in Kentucky, Virginia, Wisconsin, and other states, there is little documentation on its history in West Virginia. There is a possibility that hemp was grown in western Virginia (now West Virginia) and would be recorded in their records. There is some record of pre-statehood that western Virginia was growing this crop, but after West Virginia gained statehood in 1865, there is little acknowledgement of this crop. Due to the difficulty in accessing these records, this documentation has yet to be found by the researcher personally.

\section{Sustainability}

Sustainability is a multi-faceted idea that can encompass many areas of life and describes the relationship between the environment and society. In 1987, sustainability was defined as equal treatment of the present and future to preserve the future and utilize our resources in an efficient manner (Pearson \& Nasby, 2008). After the Rio Declaration in 1992, sustainability became clearer in its meaning when its topics of concern were "possible environmental damage, loss of biodiversity, and the like" using means of efficient production and preservation (Pearson \& Nasby, 2008). The efficiency will allow us to meet our needs currently and develop better plans and allocation of our future resources (Kuhlman \& Farrington, 2010).

Many researchers, developers, policy makers, and even community members may take this definition without question. There is, however, another aspect to the usual definition of sustainability that focuses on the ethics of sustainability. This perceived discrepancy asserts that the definition of sustainability - taking advantage of what we can now, socially, without infringing or compromising the rights of future generations to do the same - is riddled with 
values and standards that will differ for each generation (Vucetich \& Nelson, 2010). One era may concentrate on the finances they can provide and earn while another may focus on family, friends, and social outlets. Another may be completely invested in how they can best preserve their natural resources. Each generation will have different values and standards.

Some individuals question that based upon this, if there can even be a standard for sustainability as it is typically defined. If each generation will be different, and the current society will simply create their own standard, then sustainability standards will constantly be evolving. Sustaining the land is not a new concept. From antiquity to modern day, humans have experimented and migrated to preserve land and provide for their society (Pearson \& Nasby, 2008).

\section{Sustainability of Industrial Hemp}

Industrial hemp is very compliant to the definition of sustainability. In addition to its adaptation to many different growing climates, it is also self-sufficient in growing as it covers ground quickly. It eliminates the need of pesticides and herbicides and has deep roots that take advantage of the natural nitrogen in the soil (Bouloc \& van der Werf, 2013). Industrial hemp also absorbs the carbon dioxide that is released in its growing season with the next crop that is planted. This way, there are few emissions throughout its growing cycle as it absorbs an equal amount with the next crop.

Besides these advantages, industrial hemp crops also take a significant portion of heavy metals from the soil and prevent erosion with their long tap roots. Once the crop had been harvested, the leaves can be left on the soil, or tilled into the soil, as a natural restorer of the nitrogen levels that have been used. Using this method of self-sufficient fertilization, industrial hemp becomes, not only an easy crop to grow, but also a sustainable one. Its ability to be grown 
on the same land each year negates the need to cultivate another field which may require the destruction of forested areas or other crops to plant industrial hemp. Industrial hemp can produce more fiber per acre than cotton and can be grown in a variety of climates. This makes it easily accessible for farmers that wish to invest in this crop.

Communities that need economic growth could potentially benefit greatly from this crop. Even areas that may not have the climate for more delicate crops would have the opportunity to grow industrial hemp. Universally, industrial hemp crops have proved to be economically invaluable for struggling communities (USDA, 2000). Researchers at several universities across the United States are conducting research on the economic properties of industrial hemp. Some are hosting field days so that the local community can participate in learning more about this important crop (Hoose, 2016).

\section{Legalization of Industrial Hemp}

Despite the many advantages of industrial hemp, it faces great debate in North America. Because it was perceived that industrial hemp and marijuana contained equal values of THC, the two plants have been combined under one classification. The process of prohibiting the growth by the United States government of industrial hemp began in 1937 with the Marijuana Tax Act (USDA, 2000). This act did not outright prohibit its growth, but enforced a tax, penalties, and provision enforcements on the sale or dispensing in any way of hemp or marijuana. Any sale of Cannabis sativa required the seller to file a form with the Internal Revenue Service and pay the tax upon the plant (Marijuana Tax Act Law and Legal Definition, 2016).

Although there is no founded cause for limiting industrial hemp, the social theories surrounding it are abundant. In the 1930s, the process of manufacturing industrial hemp was relatively cheap and quick due to improvements in the manufacturing system. Some pose that the 
incentive for limiting industrial hemp was because William R. Hearst and Éleuthère Irénée duPont stood to lose millions of dollars or close completely if hemp could fulfill its potential in paper or for medicinal purposes (U.S. Hemp Co., 2016). Their standing and influence meant that their voices would be heard more clearly over those of the farmers seeking to improve their situation.

During World War II, industrial hemp growth was encouraged by the U.S. government and about 400,000 acres of industrial hemp were cultivated. When the Philippines and other pacific island countries fell to the Japanese, the import of rope and cordage from these islands slowed and domestic growth of industrial hemp became necessary. Although there was no change to the 1937 Tax Act, more farmers grew industrial hemp and were not registered. The influx of unregistered hemp farmers not paying taxes prompted the government to consider it a criminal offense (U.S. Hemp Co., 2016).

Under the Nixon administration, industrial hemp came under stronger regulation when it was prohibited under the Title II of the Comprehensive Drug Abuse Prevention and Control Act of 1970 (U.S. Department of Health and Human Services, 2016). During this time, a war was being waged against drugs and hemp with its relation to the Cannabis sativa family, was included in the Act. The Act had several different titles indicating different levels of drug types and their associations. Industrial hemp fell under Title II-Schedule 1, drugs that were considered the most dangerous.

Industrial hemp production eventually slowed to a standstill as it became more difficult for farmers to produce. Lack of processing plants and little encouragement from the outside resources brought its growth to an almost 80-year freeze. In 2014, the Farm Bill allowed the legalization of industrial hemp growth for research, pilot, or commercial purposes ( (Hoose, 
2016). However, the time span between the 1937 Marijuana Tax Act, Comprehensive Drug Abuse Prevention and Control Act, and the 2014 Farm Bill has left a gap where little information can be found on the growth, processing, and potential of hemp over the years (National American Industrial Hemp Council, INC. , 2016). In 2015, the Industrial Hemp Farming Act of 2015 was introduced that would exclude industrial hemp from the Controlled Substances Act's definition of marijuana (Congress.Gov, 2016).

\section{Legalization of Industrial Hemp in West Virginia.}

In 1931, West Virginia enacted a provision under the West Virginia Industrial Hemp Development Act of 1931. The provision stated that any individual desiring to grow industrial hemp must meet the federal requirements concerning the production, distribution and sale of industrial hemp prior to being licensed to grow hemp for industrial purposes in the state. This provision was amended in 2013 changing the statement so that only an application to the commissioner of agriculture would be necessary. However, the provision states that only those associated with the Department of Agriculture or institutes of higher learning are eligible to apply (West Virginia Legislature, 2016). For the new provision, industrial hemp was defined as, "Industrial hemp that has not more than one percent tetrahydrocannabinol is considered an agricultural crop in this state if grown for purposes authorized by the provisions of this article (West Virginia Legislature, 2016).The amended bill was effective ninety days after its passage on June 6,2014 , legally removing the 1931 provision and establishing a regulated industrial hemp industry (West Virginia Legislature, 2016). Pending the Industrial Hemp Farming Act of 2015, farming industrial hemp in West Virginia is limited to the public.

However, organizations both state and nationwide have sprung up to promote the public's interest in this crop and to try and increase awareness that industrial hemp is both desirable and 
profitable. A nationwide campaign is dedicated solely to increasing awareness of industrial hemp. Called "Grow Our Future", the campaign sponsors a Hemp History Week offering activities, workshops, and seminars on industrial hemp. The grassroots sponsors for the campaign come from all walks of life, but with one goal for awareness and legalization in mind for industrial hemp. In 2016, Hemp History Week reached a record of 2,000 events across all 50 states and concluded with 300 unique press coverages (Stansbury \& Moylan, 2016).

In West Virginia, the West Virginia Hemp Farmer's Cooperative (WVHFC) is comprised of veteran farmers, researchers, and politicians who are focused on the development of a supply chain for industrial hemp in West Virginia (West Virginia Hemp Farmer's Cooperative, 2016). The cooperative provides a place for those either attempting to grow industrial hemp for research, pilot, or commercial purposes, those merely interested, or those actively involved in the political aspects a place to convene with similar geo and demographics. The WVHFC publishes several reports and updates on industrial hemp in general, tips on growing, and the progress is has made through the courts.

\section{Stakeholders in West Virginia Hemp}

The membership lists for these organizations supporting industrial hemp show primarily two groups that seem to be stakeholders in industrial hemp - small farmers/business owners and the Department of Agriculture (WVHFC INC., 2016). Those that are actively growing industrial hemp are often employed in some other way so that they can promote this crop. While there are assuredly other supporters along the way, these two groups are primarily the ones who are active members of groups that are registered with West Virginia. 


\section{Future Opportunities in Research}

There are several areas in the literature for this research that need further compilation and development. These avenues of research opportunities would be useful for anyone working in this field and increase the body of knowledge about the subject. The compilation of hemp growth and production history in North Central West Virginia would be beneficial so there would be a concise document of past use of this crop. Additionally, a more in depth analysis and description of the processing of industrial hemp and the availability of processing plants. Specific research into the benefits of industrial hemp used in products - specifically, health, plastics, cosmetics, and food sources - rather than general statements. There are also several gaps in literature from the 1930's to the present about legislation concerning small farmers growing industrial hemp. These topics need further research for a clearer understanding of the historical significance of this crop and how that could influence the crop today.

\section{Research Question}

This research project is studying the attitudes, perceptions and experiences that stakeholders in West Virginia have about industrial hemp and its end uses, specifically textiles. From the literature, there is a gap in the information about West Virginia stakeholders in industrial hemp. Because of this missing information, this research will attempt to fill a portion of that gap, adding to the body of knowledge about those individuals. 


\section{CHAPTER III}

\section{Methodology/Theoretical Framework}

\section{Phenomenology}

Phenomenology is the study of phenomena, experiences, or concepts describing the way these factors exist as an integral part of the world that we live in (Astalin, 2013).

Phenomenological research is exploratory, finding gaps, asking questions, and probing into how humans in certain situations function. This type of study allows the researcher to observe, raise awareness, and gain insight into the situation without necessarily providing any solid, definitive explanations. When used as a methodological framework, phenomenology seeks the reality in an individual's narrative of their lived experience in a certain phenomenon, experience, or concept (Cilesiz, 2009).

Edmund Husserl, exasperated with the naturalism, psychologism, and historicism of the $19^{\text {th }}$ century posed that there was a new way of examining life. He developed a new philosophy that was a descriptive psychology that allowed for the observation of life without a concrete end. This allowed for the development of life and individuals, could connect them through development over years, and tie together shared experiences. Instead of there being any one answer to the situation, Husserl described a philosophy that examined individuals and situations through an analysis of mental events and self-reflection (Bertoldi, 1977).

While Husserl is credited as being the founder of phenomenological thinking, his theories were added to and reframed by many other including Merleau-Ponty, Jean-Paul Sartre, and Gabriel Marcel. Merleau-Ponty, upon reading Husserl's work, thought that phenomenology was rather a reflection on itself. If a person was observing how a situation or an individual functioned through mental events, but the observer was required to self-reflect upon that, they were 
performing their own mental experience (Bertoldi, 1977). Sartre believed in phenomenology coupled with his idea of existentialism. His idea diverges from Husserl in that Sartre was concerned with the idea of human existence itself and an ontological approach of what it is to be human and that there was little meaning to life (Onof, 2016). Marcel became an opponent of this view when he converted to Catholicism and while he promoted the idea of the human experience, he argued that there was a purpose in life that was worth studying the human experience (Hernandez, 2016). Regardless of their views on phenomenology, each of the philosophers was concerned with the idea of the lived experience of humans.

\section{Lived experience.}

Lived experiences are widely different depending on the participant's interpretation of the phenomenon, experience, or concept and their background information. A teacher in academia that has just started their first position is going to have drastically different experiences as opposed to a teacher that has taught for 20 years. The new teacher may feel unsure about certain rules, policies, how to handle students, and struggle to find their teaching voice. A more experienced teacher will have determined these elements earlier. While the new teacher will develop, and change their experiences over time, at that moment, he/she will have different experiences from the other teacher. This type of experience can be studied over time as they develop. While the study may not provide any solid answer for everyone's acclimation to academia, it can examine each individual and make connections between those experiences.

Typically, most phenomenological researchers can focus on two interconnected pieces of a participant's view - the elements and the concepts. Elements represent the actual subject matter that is causing the phenomenon. Concepts are how individuals or the surroundings respond to that element. In the example, the concept would be the teachers responding to the element which 
would be the academic background surrounding them. Each will have different reactions, but there may be certain connections that could be drawn between them possibly in educational background, how they respond to that experience in private, or what their communication or teaching style is. In this research, the element would be industrial hemp which is the subject matter. The subject matter, industrial hemp, is causing the concepts (stakeholders) reactions through their attitudes, perception, and experiences to that element of industrial hemp.

\section{Lived experience in research.}

Using a phenomenological research approach studying the lived experience of the participants has been used for a variety of subjects. For example, Jennifer Sherman and Rayna Sage (2011), studied the effects a severe economic collapse had on a community. They used a lived experience study to determine how the community perceived their loss, what they thought the causes were, and how they wanted their families to respond with education and leaving that community. Using a series of open ended, semi-structured, interview questions, the researchers used several themes that the participants could expand on or add to so that they could take whatever direction they needed (Sherman \& Sage, 2011). Although this was also coupled with the researchers living on an extended case with the community in tandem with the lived experience, most their research was based on the interviews. This type of study allowed for the situation and individuals to be studied on their reactions to the economic collapse and provide an intimate narrative of their experiences and how they were coping with the situation.

Another study utilized this approach to study attitudes of youths in a Boys and Girls Club. Using interviews, immersion, and photographic analysis, Nancy Deutsch studied the idea of moral identity, social relationships, and transformation among the individuals (Deutsch, 2005). By using this method, Deutsch could follow the youths for four years and see their 
experiences as they aged. She found that this way enabled her to see them in that habitat of the club, to interact with them naturally, and hear their stories. Using a photographic analysis, she had the participants take pictures of images that were important to them - people, places, or things (Deutsch, 2005). She found it was important to not only study the experience, but provide some type of visual connection with them that they could relate to.

Each of these studies utilized a phenomenological, lived experience method of research. For this study, phenomenological research is essential in delving into the culture surrounding those actively involved in industrial hemp. The lived experience that focuses on the personal stories of those individuals is invaluable in understanding how the stakeholders are reacting to this crop. Their stories, with the corresponding material, will show the researcher how each participant is uniquely coping. In addition, with preserved individuality, there may be similarities between them that develop into themes.

\section{Mind Mapping}

The above-mentioned idea of using a visual connection can be related to the concept of mind mapping. This method was advocated by Tony Buzan, a mathematician, psychologist, and brain researcher as a technique for taking notes and making those notes interesting visually (Brinkmann, 2003). Mind mapping allows concentrated, interesting, engaging, and organized way for the researcher to pursue different themes that they are interested in studying the participant's reaction to. Mind maps use a central idea that is surrounded by connected branches of associated topics (Jain, 2015).

The following model provides an example of how mind mapping can organize and connect data. While the central idea is transportation, it has branches that can facilitate travel through land, water, or air. These branches are further broken down into different ways that each 
of these can happen. For example, traveling by land can take place through a variety of ways including foot, car, bicycle, motorcycle, etc., but each of these is a mode of transportation. Mind mapping was introduced as a form of research by Joseph Novak as a special graphical way to relate concepts to the individual. For a researcher, this can be a way to let the participants relate their experiences and associations within the researcher's field of interest (Brinkmann, 2003). Novak based this value of mind mapping in research from a statement by Ausubel that challenged the teacher to find that most single important factor that the learner already knew and teach them from that knowledge base (Brinkmann, 2003). It has been used primarily in research education to study how students learn. With the advent of new technology and software programs to aid in mind mapping administration and results, mind mapping is being used much more frequently in qualitative research. There are some limitations to mind mapping. Mind maps can get confusing when they are crowded and not organized well. This defeats the purpose of organized data, but with proper attention to detail and awareness that this could be a potential limitation, can be avoided.

\section{Mind Mapping in Research}

Although mind mapping has been used primarily in research that is attempting to analyze study habits, scores, and categorizing data, it is an exceptional tool to use in this research. Because it allows the research participant to visually organize the end uses they associate with industrial hemp and can help them plot out which they think is the most important. By using the branches from the central theme, they can associate adjectives or associations with each end use to plot out the economic viability. 
A study completed by Orhan Akinoglu and Zeynep Yasar used mind mapping to document the effects that note taking during a science course had on students' attitudes, academic achievement, and concept learning (Akinoglu \& Yasar, 2007). Three different types of mind mapping were implements to study the effects of mind mapping on student motivation for learning the material (Jones, Jennifer, Britta, Petrich, \& Koonce, 2012). The researchers utilized the MUSIC Model of Academic Achievement which focuses on five characteristics: empowerment, usefulness, success, interest, and caring.

Mind mapping can also be used as a means of verification of an emerging framework. Whiting and Sines (2012) published a study researching the use of mind maps that sought participant verification for an emerging framework. The study used exploratory interviews that were based on three themes that they had already identified - impact, need for support, and meaning - that used groups of parents with children that had disabilities or complex health needs. Using mind mapping with stakeholders, as this study on industrial hemp is doing, considers the very meaning of being a stakeholder (Hjortso, Christensen, \& Tarp, 2003). This method is a way to provide an efficient way to obtain holistic, critical observations and attitudes from those participating (Hjortso, Christensen, \& Tarp, 2003).

\section{Appropriateness of Research Methods}

While there are many methods for conducting research, these methods of semi-structured interviews and mind mapping are the most appropriate. The research instruments of interviews and a mind map allow for a more thorough investigation and expression of the participant's attitudes. Mind maps are a way for the participants to not only think about the information, but to visually see how it can relate to their own associations (Novak \& Cañas, 2006). They can give answers that are completely their own thoughts and not performed with a close ended question. 
Each question on the interview is structured so that it allows for discussion and not a simple yes/no answer which can staunch the participant. They may choose to say yes or no, but those who want to give more descriptive information are not halted by the question itself. Kvale and Brinkmann (2015) discuss semi structured life world interviews which obtain descriptions of participant's lives revolving around a certain phenomenon. For this research, this type of method fits perfectly as it conducts a phenomenological study of lived experience. There is a certain phenomenon (the rise of interest in industrial hemp) that does not have any solid, definitive explanation. The responsibility of this research is to find out the lived experiences of those involved individuals to attempt to showcase some of the attitudes surrounding that experience.

To collect data for this research, a semi-structured in person interview was conducted by the researcher. It was paired with a mind map that asked the participant to write their associations with various end uses for industrial hemp. In accordance with the Institutional Review Board, the participants received a cover letter indicating their participation and ability to withdraw at any time. The research project was approved by the IRB \#1609297023 with Exemption 2 status. The interviews were conducted via Skype, audio recorded with Audacity, and transcribed by the researcher into Word documents. The goal was to obtain at least six research participants that were selected through a snowball effect. Given the collective nature of industrial hemp stakeholders and their connected organizations, starting with one individual lead to others willing to talk about their perceptions and interests.

\section{Participant Selection}

The participants in the research are stakeholders in industrial hemp in West Virginia. Stakeholders are defined as those persons who are actively involved in any aspect of industrial hemp, whether in farming, retail, political, or other. The participants were gathered through a 
snow ball effect where each new participant referred the researcher to another possible participant. While this may be a limitation, for this study it was essential as the participant pool is so small. A participant was contacted using the West Virginia Hemp Farmer's Cooperative. This contact then referred the researcher on to other possible participants. There are few options of those to interview as well as those who are possible participants are often difficult to find due to their smaller scale operations and their information is not easily attainable through other means.

\section{Pilot Study}

Pilot studies are a way that the research instruments can be tested to check their reliability, clarity, and effectiveness in preparation for the full study. This allows for the researcher to try out the techniques on the test run so that they can be modified or changed if need be. For this research, a pilot study was executed to test the interview questions and mind map. This specific pilot features one interview conducted to test the research instrument for clarity of questions and as a test run for the mind map, included below. The interview is formatted to gain information from the participant related to their experiences, attitudes, perceptions, but does it in such a way that their names and specific connection to the crop is not discernable. This is done to protect the confidentiality of the research participant - not only their names, but also so that their marketing and long term projected goals are not used by others. For this interview, the researcher did not go into it with the idea of doing more than one interview across which themes would develop. The purpose of this was to test the instrument for clarity and to see if it was getting the information of the participant's experiences, stories of their involvement, vision, and excitement for industrial hemp. No probing questions were asked, specifically using only those listed on the interview sheet to check them for clarity, order, and accuracy. The end question focused on industrial hemp 
as a textile and how it is seen in this use by the participant. The researcher is not advocating either way in the interview for an answer, but the participant can answer as they choose. This participant was very thorough in their answer:

I think industrial hemp is the best textile source. There's a huge, lack of infrastructure and investment capital in terms of textiles in America and/or West Virginia. Um, I do see that there's probable opportunities with some old closed down mills, uh, coal plants, or whatever, all this unused rust belt properties, if there were some seed funding, uh, business type incubator type organizations and cooperatives of people who could get together and reinvigorate that lost industry. As long as we're competing with countries like China, it's near impossible to recreate a textile industry. There's too many variables involved, in terms of large, uh, corporate involvement, and investment and infrastructure to make that a realistic industry opportunity.

Not only did he state his stance, but also the potential problems with it being used in this capacity. This is important for a researcher to have not only the experiences or the participant's, but information on where they see potential problems and challenges for both now and in the future. The pilot study showed that the researcher could acquire the needed information from the listed questions without additional ones. They were structured in such a way that the participants can answer anything without any probing. Following the pilot study, the researcher conducted four more interviews using the approved protocol. While only half of the participants returned the mind maps, the maps returned are possible indications of the end uses participants want industrial hemp used for. The Findings chapter was returned to the participants for member checking.

\section{Analysis and Corroboration}

The interviews were conducted through Skype and recorded with Audacity. The researcher transcribed them individually into Word documents, noting similarities and differences as they were each transcribed. After transcription, the interviews were read individually twice and marked with a word/s that described the answer to the question. For 
example, in a question targeting their involvement and support, the words "lack of communication" might be used. The researcher began noting how these words were being used with each of the interviews and began looking at the four answers to a question as a whole. The researcher then read the interviews together and took notes of what themes were emerging across the interviews. Following these readings, the researcher compiled the themes together and chose quotes from the interviews that best supported the theme.

The researcher found that themes were not contained only in the interview category, but were consistent throughout the interviews. For example, a theme that is present in the Knowledge category is also present in Involvement and Support. Therefore, the researcher has taken the main themes overall from the interviews. This allows the information to not be broken up to fit into one category, but to be true to the integrity of the participant's words and thought processes. Additionally, a text analysis of industrial hemp literature corroborating each theme will be used to show the collaboration between the stakeholder's experiences and its agreement or defiance of literature. To refresh the ideas being addressed, a brief synopsis of each section will be helpful for the reader (see Table 2). 
Table 2

Summary of Interview Questions and Categories

\begin{tabular}{ll}
\hline Category & Question \\
\hline & Tell me about what you know of industrial \\
& hemp's growth, processing, end uses, and \\
challenges? & \\
Which of those stood out to you the most \\
as being a key piece you wanted to know \\
more about?
\end{tabular}

Knowledge Base

Once you were interested in industrial hemp, how did you become involved? What can you tell us about the steps you took to pursue this area you are involved in?

Currently, what is your affiliation, role, or association with industrial hemp?

Involvement and Support

Anything you would do over again or change about your experience with industrial hemp?

Where would you like to see industrial hemp go in West Virginia? What is your vision that you have for this crop in this

Future of Industrial Hemp in West Virginia state?

What are your thoughts on using Industrial Hemp as a Textile industrial hemp as a textile source?

The first category for the interviews was Knowledge Base. This section's intent was to find out how the participant first heard about industrial hemp, what the participant's knowledge was about industrial hemp's growth, processes, challenges, and end uses. The section also asked what part of industrial hemp's existence did they want to know more about, how they got involved and the steps they did to become involved, and what their affiliation or role was 
currently with industrial hemp. Participants were very involved with this section and some answer components will be seen in other categories.

Involvement and Support targeted the stakeholder's involvement with industrial hemp from how they got involved, the steps they took to pursue it, their current role or affiliation with industrial hemp, reactions and help from those around them, and their involvement with the known industrial hemp organizations. The goal of this section was to establish their experiences on getting involved and supporting industrial hemp. People have different ways of doing things and for those considering involvement in industrial hemp, knowing how others became involved, what worked for them and what didn't, is important.

The third category questioned them about their impressions on the Future of Industrial Hemp in West Virginia. Drawing from their experiences and what they have seen happen, they answered questions about where they saw industrial hemp going in West Virginia, where they would like to see it go, if there was anything they would change about their experiences thus far in industrial hemp, and what advice they had for those wanting to support industrial hemp.

As the last portion of the interviews, the last section targeted the stakeholder's thoughts on industrial hemp as a textile. The researcher appreciated the honesty of the stakeholder's who were frank about what they thought industrial hemp could be as a textile. While most were positive of its appeal as a textile, there were also some who were concerned about a ready market for it as well as availability. This question will be discussed later as it is a main component of this research. 


\section{CHAPTER IV}

\section{Findings and Discussion}

\section{Participants}

At the beginning of this study, the researcher had anticipated conducting at least six interviews. However, because of time, schedules, and the lack of available participants, only four interviews were carried out. The interviews were conducted via Skype, rather than in person. This was due to the remoteness of some individuals, lack of meeting places, and, again, scheduling conflicts where a phone call fit into the participant's day more easily than a visit.

The participants in the research were stakeholders in industrial hemp in West Virginia. Stakeholders are defined as those persons who are actively involved in any aspect of industrial hemp, whether in farming, retail, political, or other. Participants were obtained from a snowball effect and through the membership lists of the West Virginia Hemp Farmer's Cooperative. Many of them had previous experience in retail, business, medical, political, or academic fields and thus contributed to their knowledge of industrial hem drawing upon their field of expertise. The participants, who were all males, will be referred to as Mr. W, Mr. X, Mr. Y, and Mr. Z for the

protection of their information. In general, each of the participants had been aware and learning about industrial hemp for close to and over ten years. See Table 3 for a highlight of some of the stakeholder's characteristics. 
Table 3

Characteristics of Stakeholders

\begin{tabular}{llll}
\hline Name & \multicolumn{1}{c}{$\begin{array}{c}\text { Knowledge of } \\
\text { Hemp in Years }\end{array}$} & \multicolumn{1}{c}{$\begin{array}{c}\text { Role in Industrial } \\
\text { Hemp }\end{array}$} & $\begin{array}{c}\text { Affiation with } \\
\text { Industrial } \\
\text { Organizations }\end{array}$ \\
\hline Mr. W & $25+$ & $\begin{array}{l}\text { Grower, Retailer, } \\
\text { Political, Grower, } \\
\text { Advocate } \\
\text { Mr. X }\end{array}$ & Yes \\
Mr. Y & $25+$ & $\begin{array}{l}\text { Scientist, } \\
\text { Researcher, Grower } \\
\text { Retailer } \\
\text { Entrepreneur, } \\
\text { Advocate }\end{array}$ & No \\
& $6-10$ & Yes \\
\hline
\end{tabular}

\section{Data Analysis Strategy}

Upon completion of the interviews, the interviews were transcribed into Word documents. Each transcript was read multiple times using the categories of Knowledge Base, Involvement and Support, Future of Industrial Hemp in West Virginia, and Industrial Hemp as a Textile, to keep the information together and to be concise so the participant's responses would not become tangled. The transcripts were then reread, highlighting and noting significant or similar phrases, concepts, words, or descriptions in the transcriptions. Within the interviews, keywords and phrases emerged showing developing themes and commonalities. Block quotes from the interviews are used throughout this section so the reader will be able to get the full, immediate, and pertinent quotes, without the researcher skewing the meaning by paraphrasing. The Findings chapter from this research was sent for member checking. None of the participants responded with any feedback or concerns that they had with the findings.

From these categories of Knowledge Base, Involvement and Support, Future of Industrial Hemp in West Virginia, and Industrial Hemp as a Textile, there were several main themes 
generated across the interviews; Finances and Affordability, Infrastructure and Marketplace,

Communication, Latent and Extended Knowledge, and Awareness (see Table 4).

Table 4

Themes and Supporting Responses

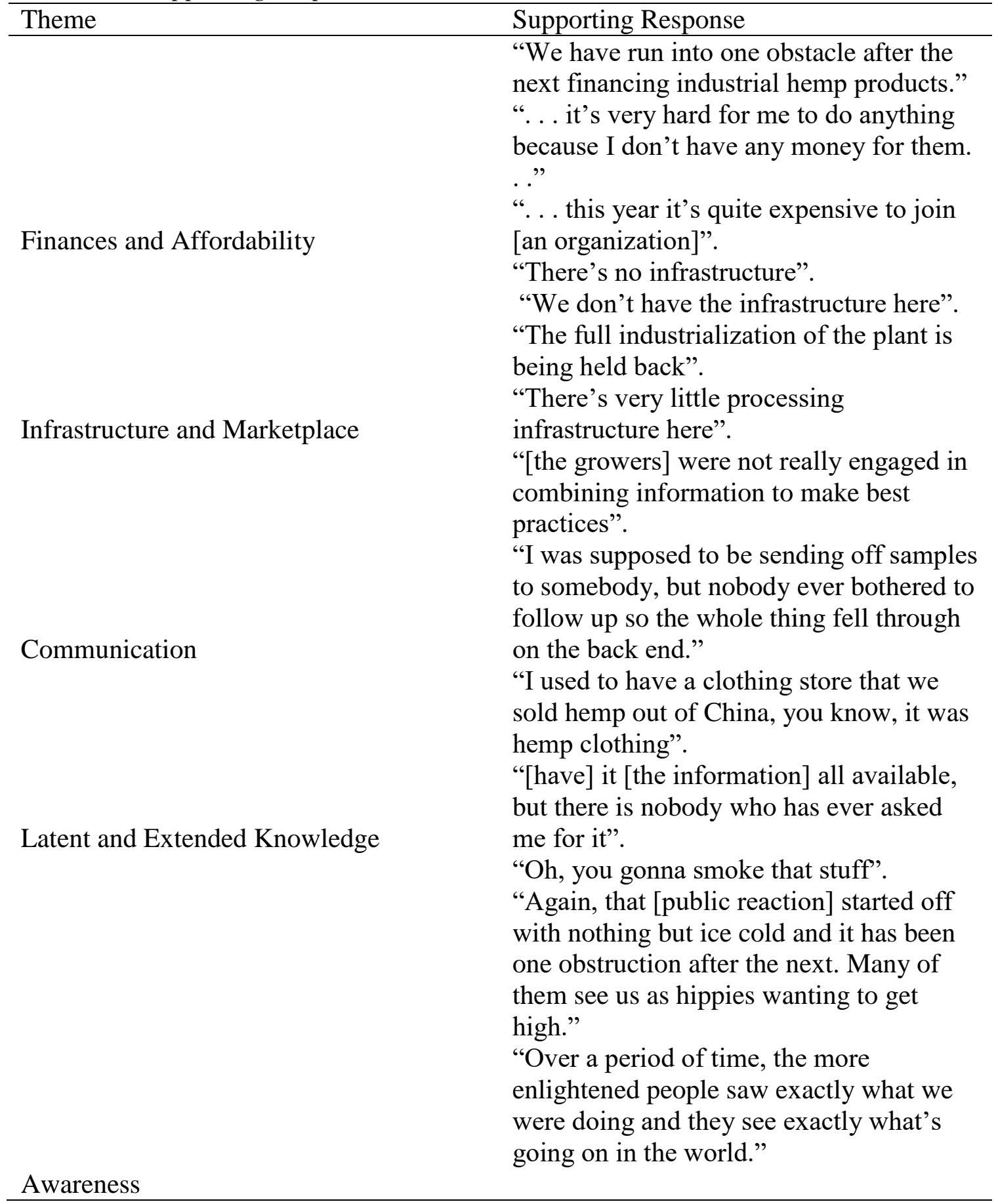


After these themes are explained, there will be a discussion on the stakeholder's opinions and experiences with industrial hemp as a textile. Three of the stakeholders identified with the West Virginia Farmer's Cooperative, while the fourth one was not a member, but supported their activities. The literature on the Farmer's Cooperative is qualitative literature put out by the Cooperative and their associates and is supported by institutions, advocates, and researchers. Due to this, the literature being used will come from this source and be used as a qualitative, text, analysis for all four stakeholders.

\section{Finances and Affordability.}

An issue with many developing crops, products, businesses, etc., is lack of ready capital. Industrial hemp's development is no different. There is little funding for the industrial hemp experiments or crop and the stakeholders are investing their own money into the endeavor. Per Mr. Z, "We have run into one obstacle after the next financing industrial hemp products". Even at institutions sponsoring experiments, the individual uses their own money or external funding to finance their industrial hemp project. Mr. Z says that he is, “. . . trying to get external money to continue the work that we started ...". Although there are hopes for external funding and greater investment stability, Mr. Z fears that they will not be able to continue without financial help:

... it's very hard for me to do anything because I don't have any money for them. . I I will make a concerted effort over the next year to get external funding and if I can, then I can continue our research. If I can't, it will probably limp along, may or may not without me, just depends.

Aside from the cost of seed, workers, harvesting, tools, and land, there is also a cost to join the organizations, such as the West Virginia Farmer's Cooperative and the Hemp Association, 
created to help stakeholders. Mr. Y said that, “. . . this year it’s quite expensive to join [an organization]". Association fees run from a Supporter fee of $\$ 50$ to well over $\$ 1,000$ for a Business level. However, a Supporter fee does not give access to website or a directory listing which would limit the interaction of a Supporter. Stakeholders find themselves stretched thin to cover cost of the equipment as well as membership in organizations that will help them with networking and advice. Mr. Z said that he could:

... take a couple million dollars and go to a free state like California, Oregon, Washington, or Colorado and open up a grow facility and grow some of the strongest cannabis on the planet, you know, just real cannabis, but if I were to put in a thousand-acre field of hemp and put a factory at the bottom of the hill, I'd be in big trouble...

The Farmer's Cooperative's website expressed concern that economic feasibility was not easy to calculate in West Virginia. This is because industrial hemp is only allowed to be grown on research plots and not for production (West Virginia Farmer's Cooperative, 2017). Production would calculate in harvesting, processing, and manufacturing costs. The article suggests that there are ways to estimate costs for manufacturing industrial hemp and provides informational tables. While the stakeholders did not necessarily delve into the economic profitability in great specificity, there is agreement between the literature and the stakeholders. There is a great cost involved with industrial hemp because it is still relatively new to the area. Additionally, there is great perceived economic potential, not yet known in facts and figures, as well as some personal finances involved in putting this crops in the fields (USDA, 2000). It also directs analysis into another theme emerging, that of lack of infrastructure on West Virginia.

\section{Infrastructure and Marketplace.}

For the stakeholders, infrastructure is the built environment of structure, systems and facilities necessary to get their industrial hemp harvested, processed, and manufactured into 
whatever end use is needed. Each of the stakeholders were unanimous in agreeing that West Virginia had a severe lack of infrastructure illustrated in such comments as, "there's no infrastructure", "we don't have the infrastructure here", "the full industrialization of the plant is being held back", and "there's very little processing infrastructure here". Each of these quotes is built upon their experience growing industrial hemp and that harvested resource being laid waste because there are no processing facilities provided in West Virginia. Those that could harvest say that, “[there] is processed material that we can't do anything with because there's nothing in the law that allows us to do anything with it at this point".

Currently, while there are no processing plants in West Virginia, there are also no laws allowing the stakeholders to process the crop. Expenses prohibit the growers from transporting their crops and federally, it would be illegal for them to take the crop across state lines because of it cannabis family connection. For the crop to reach its full potential, there needs to be guidelines or rules in place allowing for the processing of industrial hemp in West Virginia. The stakeholders also see the lack of infrastructure as halting their economic growth. Mr. W was concerned, "... because the infrastructure is not really allowing us to [have economic profit] at this point, we kind of have to do our research, growing and getting the infrastructure put into place and that's the challenge right now".

Scholars from the University of Kentucky have compiled an article detailing the finer points of industrial hemp in its growth, processing, and economic uses. They particularly point out that, in Kentucky and any state implementing industrial hemp as a new crop, there is a, "need for processing plants to process hemp from field production, and the apparent lack of such industry in the U.S., substantial infrastructure development would be required for profitable U.S. farm production" (Kaiser, Cassady, \& Ernst, 2015, pg. 2). The date on this article from two years 
ago shows that this is still an issue for these states developing industrial hemp crops. It is accessible through the West Virginia Farmer's Cooperative website.

\section{Communication.}

Already a hot topic because of its political and cultural significance, the stakeholders have found that communication is important for industrial hemp. Lack of communication causes misunderstanding between the stakeholders who may perceive each other differently. Networking with other stakeholders in the area was a way that the interviewees built relationships with each other and learned about best growing practices, imagined the future of industrial hemp, and challenged each other to keep going.

There was a slight disagreement and lack of communication between the stakeholders and research institutions on how they were to grow the 2016 hemp crop. Mr. Y said that the growers that he had been working with, "were not really engaged in combining information to make best practices. . I'm not disparaging anybody - I think they just wanted their seed and wanted to do what they wanted with it". Other stakeholders said that they lost contact with other research facilities and could not contact them. Mr. W grew industrial hemp last year and expressed his interactions as close to disastrous:

I was supposed to be sending off samples to somebody, but nobody ever bothered to follow up so the whole thing fell through on the back end because there were no results of anybody following up on what I discovered in terms of my growing hemp.

This difference in viewing the procedures and collaboration for growing industrial hemp, is a reminder to keep the communication open between all stakeholders for the best possible advancement in this crop. 
While there is a scarcity of research of communication within the industrial hemp community, two articles had interesting references to networking to have the best industrial hemp crops. Stakeholders were encouraged to contract their seed with a reputable company who knew what their varieties were. This way, they would know what varieties they were getting as well as have the best seed purchasing experience with industrial hemp (Hemp Oil Canada, 2006). Knowledgeable sellers who could help and guide the grower were benefits to working with a reputable company. Additionally, the other research article worked with surveying individuals to gauge their interest and desire to be involved and communicate in the industrial hemp community (Minnesota Department of Agriculture, 2015). Their results showed that many individuals had the desire to become involved, but lacked the resources or opportunity to do so. The researcher does not want to stretch the articles to fit into the area of communication, but they do show that communication and networking are important. Industrial hemp communities need communication to pass on their knowledge and to grow. The public needs communication to be informed and take part in the industrial hemp movement.

\section{Latent and Extended Knowledge.}

An interesting aspect from this research that had not been anticipated was an idea of a latent and extended knowledge. For this study, latent knowledge is knowledge that has been hidden or laid dormant for quite some time. Three quarters of the stakeholders had a long-term knowledge of industrial hemp. The stakeholder's have studied and been intensely interested in industrial hemp for over 20 years, but their knowledge of it has been negated because of bureaucratic conventions making it impossible for them to expand and grow on the knowledge

that they have. Mr. W, who became familiar with it by selling it as a marketable good, stated, "I used to have a clothing store that we sold hemp out of China, you know, it was hemp clothing". 
Mr. X was in college when he came upon an old USDA pamphlet that spoke of the uses for industrial hemp during World War II. He noted:

There was one [a pamphlet] from the 40s that talked about the benefits of hemp and how hemp can provide for or plus times the amount of biomass per acre than a wood plot or a forest and how beneficial it would be for, you know, deforestation and things like that.

The literature made an impact on him because of its environmental prospects. Though he could do nothing with the crop because of legal restrictions, he continued his interest and research into it.

There is also unused information within 2016 when the first crop was grown. Mr. W still, "[has the information] all available, but there is nobody who has ever asked me for it." This information is very important to the next round of industrial hemp farmers and researchers. It will provide them a background and knowledge of each step through its growth, processing, and manufacturing. This corroborates the importance of using this information in communicating. To save this valuable information from obscurity, it needs to be communicated and put into practice to have effective, high producing crops, ever building on the current knowledge base.

\section{Awareness.}

Public awareness of industrial hemp was a concern of the stakeholders. While much of the West Virginia population is aware that industrial hemp exists, there is still a stigma that it serves the same purpose as marijuana, containing the same THC value. Mr. W reported that even now, people will joke, "Oh, you gonna smoke that stuff", implying that there is still a possibly negative reputation affecting industrial hemp.

People have the misconception of looking at hemp versus marijuana, even though it's basically the same plant, when we talk in reference to hemp, we know it's cannabis, but it's cannabis with no THC in it. This is not a get high plant, this is an industrial plant for use in the industry. The initial reaction was always kind of joking at first, but when I started to explain, everybody really got on board. . . they've gotten to be very supportive of it. 
While public awareness is still a concern, as seen in Mr. W's above statement, there is an increasing positive reaction to industrial hemp. Mr. X terms this as a "cannabis revolution" that is sweeping across the country, due, in part, to medical marijuana bills, but also industrial hemp's increasingly active appearance on the state, federal, and local levels.

This is not to say that there had not been a struggle to gain popularity with the public for industrial hemp. There will always be skeptics for some reason and those who may at first not agree, but slowly, through outreach and education, understand the benefits of industrial hemp. $\mathrm{Mr}$. Z reflected on this change that he has seen during his time working with industrial hemp

Again, that [public reaction] started off with nothing but ice cold and it has been one obstruction after the next. Many of them see us as hippies wanting to get high. . Over a period of time, the more enlightened people saw exactly what we were doing and they see exactly what's going on in the world. Over a period of time, that message has become more and more positive. The support is just growing. It's incredible. We're no longer a bunch of hippies wanting to get high, we're agricultural and sustainable industrialists and entrepreneurs.

In keeping with the goals of their organization, the West Virginia Farmer's Cooperative offers a variety of resources for public participation in their accessibility to their literature on industrial hemp, as well as Capitol days, workshops, and hands on experiences with seminars. While these are not necessarily written literature on public involvement, the organization is actively providing means for the public to gain familiarity with the crop and increase its awareness. The Farmer's Cooperative has a public Facebook and GoFundMe page should people want to become more involved (West Virginia Farmer's Cooperative, 2017). One project that the Farmer's Cooperative is supporting is a Rx Community project, “working to provide a new prescription for substance abuse treatment and recovery in the Mountain State by providing education and new opportunities", showing one example of service to the community to promote awareness and education (West Virginia Farmer's Cooperative, 2017). The project uses 
gardening and the outdoors to help people overcome their addictions. It educates them and lets them take pride in cultivating their own gardens or preparing healthy meals. The Farmer's Cooperative's involvement is not meant to promote industrial hemp necessarily, but to help educate and support those who may be suffering from an addiction to a substance like marijuana.

\section{Industrial Hemp as a Textile.}

As one purpose of this research was to discern the views and thoughts on industrial hemp as a textile from the stakeholders, a question was directed specifically towards that end. In general, the stakeholders agreed that, while industrial hemp had wonderful properties and possibilities as a textile, the lack of infrastructure, foreign competition, and cost means industrial hemp as a textile has a long way to go. Mr. $\mathrm{X}$ thought that industrial hemp as a textile had "unlimited potential" and Mr. Y agreed, but stated that

... as long as you have the infrastructure to convert that raw plant material into a fiber, it makes a lovely textile. We think of it as a rope material, but it can be fine and soft, something you want to wear, it doesn't have to be hairy and itchy.

They saw industrial hemp as a textile as niche, high value markets, that could be profitable given the right infrastructure and marketplace. Mr. Z saw textiles as a definite possibility, but would like to see textiles in West Virginia develop hemp processing capabilities and not focus on finished goods. The fibers would be processed here and then actually finished in another state. He saw it as a potential to

... be a whole new era in American textile production. Again, this is an industry that cannot be offshored easily Other countries are already making hemp textile and cannot meet the demand. . . it will revitalize, along with American bamboo, our domestic textile industry, and that will, of course, revitalize America's garment industry.

From the stakeholders, in sum, it is discernible that while industrial hemp has massive potential as a textile, it does face some barriers that need resolved before it takes 
the forefront. Lack of infrastructure, competition with offshoring textiles, and cost from getting it started are barriers that while impressive are not impassable.

These are the five main themes that developed from these interviews. The literature with each one shows a corroboration that, while this research was confined to West Virginia, these issues are not isolated incidents. As evident from the references used for this research, the issues are nationwide in many of the states seeking to integrate this crop into their economy.

Because it is not contained, but are issues seen nationwide, this research, and other research taking place, is extremely important. It shows that there is valid information being put forth and those interested in preserving the economy of their state would do well to take notice of this crop. Industrial hemp may at first sound like a crop too hard to grow with its legalization and processing problems. However, it is inevitable that the legal pieces will be solved and this crop will be able to be grown in many states legally. Those, such as these stakeholders, will be at the forefront because they have already been doing their research on growing and processing, they have their permits to grow, and they have specific, viable ideas for end uses. 


\section{CHAPTER V}

\section{Conclusions}

\section{Outcomes and Implications}

The research provided five important themes to answer the research question, what are the attitudes and perceptions of West Virginia stakeholders towards industrial hemp and its end uses? The stakeholders are concerned with finances, affordability, communication, infrastructure, awareness, and knowledge. Lack of finances means that the stakeholders must invest more of their private resources into this crop. While they are willing, and have been doing so, external funding and crowd funding are sources that would be beneficial. High costs for this crop have been corroborated in the literature and West Virginia stakeholders would welcome, not only interest, but additional resources to help them with this endeavor.

Communication is vital to any area and the stakeholders need open lanes of communication. To avoid a year like 2016, they need to interact with their research institutions and have the resources available to collaborate on best growing practices. In order that no one feels left out, or is left with a crop that they have not been informed what to do with, the stakeholders would like to see better communication practices and networking to ensure their crops are going to do as well as they can.

While the researcher could not point to one specific article detailing the unused information of industrial hemp, the researcher would like to in sum point to all the articles pertaining to industrial hemp cited in this research. These articles have outlined specifically different aspects of industrial hemp. However, the information is unused except by other 
researchers and those struggling to grow industrial hemp. There is a great deal of research on industrial hemp, but largely only read by those who are familiar with it already. This information is not getting directly to the public. Sites like the Farmer's Cooperative are providing the articles they can and encouraging readership. In talking with the stakeholders, this theme of latent and extended knowledge is not necessarily something that will be researched -although perhaps it should be- but it is evident in the readership of the literature and talking with those individuals actively involved in industrial hemp. One way that could be pursued in making that information available is to continue expanding the library housed in places like the West Virginia Farmer's Cooperative. They have information available in their resources and if that continued to be expanded and include much of the industrial hemp research, it could provide a publicly accessible channel for dissemination of the material.

While each stakeholder had suggestions and advice for potential advocates, none of them doubted their current or future roles in industrial hemp. They each wanted to continue with their current position and advocacy, but do more as well. When asked if they could do anything over again, the almost unanimous reply was always, "no". If they could maybe tweak a few things, they wished they had more resources to put into it. They each had a strong desire for public awareness of this crop and were not content to merely sit by, but to be involved in some way to educate the public.

As a textile, industrial hemp faces challenges. Some of those challenges are ones that cannot be rectified by the stakeholders personally. Offshoring and importing cheaper fabrics that are easier to produce is an appealing process to keep up with the need for consumer goods. Another challenge facing industrial hemp as a textile would be public appeal. The public should be introduced to this fiber and have it proven that it is comfortable, durable, and will meet their 
expectations. However, while the stakeholders have implied from the interviews that, as a textile, industrial hemp faces possibly more challenge than it would from any other end use, it is still a feasible market. Once issues, such as infrastructure and finances, have been stabilized, there is a strong possibility that hemp textiles could be on the market.

\section{Limitations}

There were a few adjustments made to the research method the researcher would like to explain. The original research method had included the use of mind maps as a way for the stakeholder participants to visually associate their ideas and association with end uses for industrial hemp. As only half of the participants completed them, the researcher has included them in Appendix $\mathrm{C}$ to show the implications that could have come from a full response. One of the implications are that the stakeholders believe that the specified end uses have great potential, but are especially interest end in the medicinal uses. Additionally, the researcher had intended to conduct the interview in person, because of time, scheduling, and distance restraints, the interviews had to be conducted via Skype.

Because of this, the researcher included textual support to show the consistency of the stakeholders with literature from their organizations. This shows that their views are consistent throughout their experiences, not just shared through the interviews for this research. In addition, text analysis shows the stance of organizations they are identifying with and that they are corroborating their mission statements and outreach.

While the above adjustments provided adequate research methods, they were limitations to the study. They did not give the researcher an opportunity to be with the stakeholder and have that connection with them. Some of the interview was lost due to indiscernible audio that could 
have been kept in an in-person interview. Additionally, due to timing, schedules, and small participant pool, a larger sampling would have been desirable.

\section{Further Research Opportunities}

This study showed that there is still a need for not only current research on industrial hemp in West Virginia - and other states - but also a source of information as to the next steps that need to be taken to integrate industrial hemp as part of West Virginia's economy. Specifically, as indicated by the stakeholders, the need for infrastructure or ease of transport across state lines to process and manufacture the hemp. Additionally, there is an increased need and desire of the public to continue being informed and educated.

Even while this research was being conducted and written, changes were happening with the legalization of industrial hemp. This makes it difficult to get a complete, thorough study, but rather, this is a snapshot in time of industrial hemp's journey in West Virginia. As a further research opportunity, a similar study incorporating more stakeholders and using in person interviews, in five years of so, would be beneficial. It would provide a follow-up to see if any of the themes in this research were brought to fruition or pursued. Will there be infrastructure in place? What will communication be like in five years? Or, even, how will public opinion change in those five years' time? With the rapidly changing legalization and education pieces of industrial hemp, to document its journey would show not only its path, but the surrounding environment and lived experiences around it.

Literature has shown that industrial hemp is of economic benefit and is easily adaptable to many climates, including West Virginia (USDA, 2000). The stakeholders that are already in place in West Virginia are already using their own time, land, money, and knowledge to 
incorporate the crop. While some stakeholders are growers, retailers, politicians, or educators, they have the same goal in common; the legalization of industrial hemp in West Virginia. This study has shown the main issues that they are facing currently and explored their lives and connections to this crop. They have invested much of their life into the furtherance of industrial hemp in West Virginia and its potential economic benefit to the state. 


\section{REFERENCES}

Allegret, S. (2013). The History of Hemp. In P. Bouloc, Hemp: Industrial Production and Uses (pp. 4-26). France: LCDA.

Akinoglu, O \& Yasar, Z. (2007). The Effects of Note Taking in Science Education through Mind Mapping Techniques on Students' Attitudes, Academic Achievement and Conceptual Learning. Journal of Baltic Science Education, 6(3). doi: 1648-3898

Amaducci, S. (2003). HEMP-SYS: Design, development and up-scaling of a sustainable production system for HEMP textiles - An inegrated quality SYStems approach. Journal of Industrial Hemp, 8 (2). DOI 10.1300/J237v08n02_06

Anne, A. (1948). Hemp-Production and utilization. Economic Botany, 158-169.

Astalin, P. K. (2013). Qualitative Research Designs: A Conceptual Framework. International Journal of Social Science \& Interdisciplinary Research, 2 (1). ISSN 2277-3630

Bertoldi, E. F. (1977). Phenomenology of Phenomenology. Canadian Journal of Philosophy, 7 (2). DOI 10.1080/00455091.1977.10717016

Bouloc, P. (2013a). Hemp: A plant with a worlwide distribution. In P. Bouloc, Hemp: Industrial Production and Uses (pp. 1-3). France: LCDA.

... (2013b). The industrial hemp economy. In P. Bouloc, Hemp: Industrial Production and Uses (pp. 145-161). France: LCDA.

Bouloc, P., \& van der Werf, H. M. (2013). The role of hemp in sustainable development. In P. Bouloc, Hemp: Industrial Production and Uses (pp. 278-289). France: LCDA.

Brinkmann, A. (2003) Graphical Knowledge Display-Mind Mapping and Concept Mapping as Efficient Tools in Mathematics Education, Mathematics Education Review, 16.

Cilesiz, S. (2009). Educational Computer Use in Leisure Contexts: A Phenomenological Study of Adolescent's Experiences in Internet Cafes. American Educational Research Journal, 46 (1). DOI 10/3102/0002831208323938

Congress.Gov. (2016, July 21). Retrieved from H.R.525 - Industrial Hemp Farming Act of 2015: https://www.congress.gov/bill/114th-congress/house-bill/525

Deutsch, N. (2005). Doing the Right Thing. New Directions for Youth Development, 108. Retrieved from https://cas-ecampus.wvu.edu/bbcswebdav/pid-3392289-dt-content-rid10804198_1/courses/star86183.201608/Deutsch_2005.pdf

Fortenberry, T. R., \& Bennett, M. (2004). Opportunities for commercial hemp production. Review of Agricultural Economics, 26 (1). DOI 10.1111/j.1467-9353.2003.00164.x

Hemp Oil Canada. (2006). Hemp Agronomy 101. Hemp Oil Canada Inc. retrieved from http://www.votehemp.com/PDF/HempAgronomy101version2006.pdf

Hernandez, J. G. (2016, September 21). Internet Encyclopedia of Philosophy: A Peer-Reviewed Academic Resource. Retrieved from Gabriel Marcel: http://www.iep.utm.edu/marcel/

Hess, K. (1958). Textile fibers and their uses. New York: J. B. Lippincott Company.

Hjortso, C., Christensen, S., \& Tarp, P. (2003) Rapid stakeholder and conflict assessment for natural resource management using cognitive mapping: The case of Damdoi Forest Enterprise, Vietnam. Agriculture and Human Values, 22. DOI: 10.1007/s10460-0048275-Z 
Hoose, N. v. (2016, July 13). Agriculture News. Retrieved from Purdue University: http://www.purdue.edu/newsroom/releases/2015/Q3/industrial-hemp-production-focusof-purdue-field-day.html

Humphries, M. (2004). Fabric Reference. Upper Saddle Rive, NJ: Pearson Prentice Hall.

Jain, S. (2015). The comprehensive Study of how Mind mapping Technique Helps to Understand Concepts and Ideas in Science Teaching, International Journal of Scientific and Research Publications, 5(12). ISSN: 2250-3153

Johnson, R. (2011). Hemp as an Agricultural Commodity. In E. Clark, Cannabis Sativa for Health and Hemp (pp. 65-95). Hauppauge, NY: Nova Science Publishers.

Jones, B., Jennifer, C., Britta, D., Petrich, \& Koonce, C. (2012). The Effects of Mind Mapping Activities on Students' Motivation. International Journal for the Scholarship of Teaching and Learning, 1(12).

Joseph, M. (1986). Introductory Textile Science. Fort Worth, TX: Holt, Rinehart, and Winston, Inc.

Kadaloph, S. (2010). Textile. Boston: Prentice Hall.

Kaiser, C., Cassady, C., \& Ernst, M. (2015). Industrial Hemp Production. University of Kentucky Agricultural Communications Services. University of Kentucky.

Kuhlman, T., \& Farrington, J. (2010). What is Sustainability? Sustainability, 2 (11). DOI $10.3390 / \mathrm{su} 2113436$

Marijuana Tax Act Law and Legal Definition. (2016, July 13). Retrieved from USLEGAL: http://definitions.uslegal.com/m/marijuana-tax-act\%20/

Minnesota Department of Agriculture. (2015). Industrial Hemp Research. retrieved from https://www.mda.state.mn.us/news/ /media/Files/news/govrelations/legrpt-hemp15.pdf

National American Industrial Hemp Council, INC. . (2016, July 13). 2014 Farm Bill Authorizes Industrial Hemp Research. Retrieved from NAICI: http://naihc.org/home/332-2014-farmbill-authorizes-industrial-hemp-research

Onof, C. J. (2016, September 21). Internet Encyclopedia of Philosophy: A Peer-Reviewed Academic Resource. Retrieved from Jean Paul Sartre: Existentialism: http://www.iep.utm.edu/sartre-ex/

Pearson, C., \& Nasby, J. (2008). Sustainability. In C. Pearson, \& J. Nasby, The Cultivated Landscape (pp. 127-164). McGill's-Queens University Press.

Ranalli, P., \& Venturi, G. (2004). Hemp as a raw material for industrial application. Euphytica, 140 (1). DOI 10.1007/s10681-004-4749-8

Sherman, J., \& Sage, R. (2011). Sending Off All Your Good Treasures: Rural Schools, BrainDrain, and Community Survival in the Wake of Economic Collapse. Journal of Research in Rural Education, 26(11). Retrieved from http://jrre.psu.edu/articles/26-11.pdf

Small, E., \& Marcus, D. (2002). Hemp: A new crop with new uses for North America. In J. Janick, \& A. Whipkey, Trends in new crops and new uses (pp. 284-326). Alexandria, VA: ASHS Press.

Smith-Heisters, S. (2008). Environmental Costs of Hemp Prohibition in the United State. Journal of Industrial Hemp, 13 (2). DOI 10.1080/1537788082391308

Stansbury, L., \& Moylan, T. (2016, July 28). Grow Our Future. Retrieved from Hemp History Week: http://hemphistoryweek.com/wp-content/uploads/2016/07/7-19-16-HHW-RecapPR-FINAL.pdf 
U.S. Department of Health and Human Services. (2016, July 13). U.S. Food and Drug Administration. Retrieved from Controlled Substances Act: http://www.fda.gov/RegulatoryInformation/Legislation/ucm148726.htm

U.S. Hemp Co. (2016, July 14). U.S. Hemp Co. . Retrieved from U.S. Hemp Museum: http://ushempcomuseum.com/

USDA. (2000). Industrial hemp in the United States: Status and market potential. USDA, 1-38.

Vucetich, J., \& Nelson, M. (2010). Sustainability: Virtuous or Vulgar? Oxford Journals, 62 (3). DOI 10.1525/bio.2010.60.7.9

West Virginia Farmer's Cooperative. (2017, March 20). Retrieved from West Virginia Farmer's Cooperative: https://wvhemp.org/

West Virginia Hemp Farmer's Cooperative. (2016, July 28). Mission Statement. Retrieved from West Virginia Hemp Farmer's Cooperative: https://wvhemp.org/members/

West Virginia Legislature. (2016, July 21). West Virginia Legislature. Retrieved from Bill Status - Regular Session:

http://www.legis.state.wv.us/Bill_Status/Bills_history.cfm?input=3011\&year=2014\&sess iontype $=\mathrm{RS}$

Wilson, K. (1979). A history of textiles. Boulder, CO: Westview Press.

Woodhouse, J., \& Kilgour, P. (1919). Cordage and cordage hemp. Cheshire, England: William Kenyon \& Sons, Ld.

WVHFC INC. (2016, September 21). WVHFC INC. Retrieved from wvhemp.org: https://wvhemp.org/ 


\section{Appendix A Interview Transcription for Pilot Study}

Interviewer: How did you first hear about industrial hemp?

Participant 1: I first heard of industrial hemp probably about 30-40 years ago, uh, in my youth. I used to purchase hemp clothing, hemp shoes, um, and actually had even hemp seed early on in my teens. So I've known about industrial hemp most of my life - since I was a teenager.

Interviewer: Tell me about what you know of industrial hemp's growth, processing, end uses, and challenges?

Participant 1: Industrial hemp's growth, if you're talking specifically within the American border, it's a slow growth. There are associations and industry mavens who are working hard to get industrial hemp reclassified so it can be grown just like any other commodity, agricultural crop, soy, corn, etc. Um, hemp industry's association being a primary one, but you also have large companies who are having to import hemp from overseas to sell their products like Nativa, Dr. Bonner, uh, Bob's, Red Mill, to name a few. Um, as far as growth goes, I think it's been growing steadily year by year as more states come on board as legal industrial hemp growing states. So I think you're going to see a growth, over the next five years, probably all states will have legal industrial hemp. Just guessing on that one. Um, processing, that's a tough one, because there is really no sufficient ... efficient ... method of processing within America as of yet, other than some first time startups in North Carolina, 
Colorado, Kentucky, um, Kentucky I know is working with the Department of Agriculture, some of their state senators to fund some processing facilities, um, but it's going to take a lot of infrastructure, capital, venture capital, private investment before processing really kicks into the point where it becomes a profitable industry. Little by little it is and it will. Um, end uses ... there's too many to mention in this interview, but basic end uses, um, most people that are familiar with it and know anything about it (indiscernible) are food, health, and beauty items, um, textiles, apparel. There is some interest in the construction industry for hemp hurd and hempcrete. There's a lot of testing going on and certifications being created, so that they become products, retail products, in the construction, home building and remodeling industry, so I think that's going to be a pretty big end use eventually, once the certifications and processes and licensing and all that gets cleared. Um, the major challenge, obviously, is the scheduling on the federal level, um, even with the 2014 Farm Act, which allows legal hemp states to grow agricultural hemp, they're still bound by federal laws in terms of THC content, um, and actual end use products. Distribution, outside of the state where its grown. So it's a huge challenge until those laws are adjusted, rewritten or reclassified. We, um, any grower, farmer, or entity that's interested in profiting on agricultural hemp has to have the ability to market those products on a nationwide and international scale as opposed to a research project where you can't expand outside of your own state.

Interviewer: Which of those stood out to you the most as being a key piece you wanted to know more about?

Participant 1: Um, I would like to know more about the construction, building, home improvement, retail aspect of utilizing industrial hemp, as well as the health, food, and 
beauty markets, which are multibillion, international markets, which any tentative industrial hemp grower could tap into if given the opportunity, per the rules and regulations of being a grower.

Interviewer: Once you were interested in industrial hemp, how did you become involved? Participant 1: Once I was interested, which was actually many years ago, um, I really didn't get uh, full, fully involved until about three, four years ago when I started researching hemp textiles, hemp food, hemp beauty and health products. Partnered up with some friends who also marketed hemp products over a period of about 15 years, mostly Midwest and west coast friends. I noticed there was a gap or a hole in product availability in our region of the state of west Virginia, so my thoughts were, at the time, I could get more involved, start a business, or start laying the groundwork for a business, um, to eventually, once the regulations and laws changed and have a foothold, um, in terms of selling at the retail level, consignment stores, etc, hemp agricultural, industrial hemp products.

Interviewer: What can you tell us about the steps you took to pursue this area you are involved in?

Participant 1: Um, one of the most important steps was for me to reach out and network with the industry professionals, um, old timers if you will, that have been involved in hemp products, manufacturing, and retailing over the last 25-30 years. That includes networking with business owners from Europe, from Asia, and Canada, from France, Italy, several in America, mostly on the west coast, um, and getting, basically I pulled those people that were willing to share their information and started putting some pieces of the puzzle together in terms of how to operate a functioning, retail business in the east. So networking is huge. Interviewer: Currently, what is your affiliation, role, or association with industrial hemp? 
Participant 1: Um, currently I have a small, family business where I sell retail, wholesale, and consignment hemp products. Um, apparel, seed oil, paper, um, all .03 international, standard THC level products. Essentially, wholesale products that are legal within all United States, Puerto Rico, and Guam. . . as well as Europe.

Interviewer: What was the reaction from those around you when you expressed interested and became involved?

Participant 1: Um, lots of wide eyes, not as many as I had expected, um, I've actually had a very positive, um, inquisitive, and generally open responses from people over the last three year period. Um, if you wanted to give it to them percentage wise, I'd say $95 \%$ of the people I interact with, in all demographics, young the old are open to discussing industrial hemp and hemp products. Um, I get the occasional, "Hey can I smoke that t-shirt?" kind of response, but those are very rare at this point. So I've actually gotten a better response than I had anticipated and it's actually fueled me on to continue and expand what I'm doing. Interviewer: What types of help and support have you found in the community of industrial hemp growers, politicians, and others?

Participant 1: Very little at first. As far as support, I am part of Hemp Farmers' Cooperative, as well as the Hemp Industries Association, um, so support really came from the outside in at first. Uh, the first year, I would say there was little to no support, other than my network of friends, coworkers, and other businesses that sell hemp.

Interviewer: Have you been a part of any of the known industrial hemp organizations in West Virginia?

Participant 1: The West Virginia Hemp Farmer's Cooperative, um, the Hemp Industries Association, I'm not actually a member of it, but I support it and have supported it, as well as 
the Hemp Farmer's Cooperative with promotional products, uh, visuals, educational tools for events and participation in numerous events throughout the state.

Interviewer: Where do you see industrial hemp going in the future within West Virginia? Participant 1: I see industrial hemp being used a lot in the future. (Indiscernible) corn, wheat, soy. I'd like to see it be more available and open to small family farms, but I do see, or feel, that the ability to grow industrial hemp in West Virginia is ultimately going to be funneled into larger, more profitable entities. Um, my stance is and always has been, that we should allow small, family farms to capitalize on growing industrial hemp, um, but, unfortunately, I don't see it going in that direction currently.

Interviewer: Where would you like to see industrial hemp go in West Virginia? What is your vision that you have for this crop in this state?

Participant 1: I would like to see industrial hemp grown throughout the entire state of West Virginia, north, south, east, and west. There are hemp cultivars that thrive better in southern regions and northern regions, those can all be figured out to enhance the crop's potential. Um, I am a sort of biased in terms of the northern panhandle region, since I live up here, but I would really love to see industrial hemp, agricultural hemp expand up here and allow more farms to come back to existence. That's one of the problems we have up here is a loss of farms, so I feel the opportunity is there to recreate, or reinvigorate some of the farming industry.

Interviewer: Anything you would do over again or change about your experience with industrial hemp? Will you plan on continuing in the role you now take in industrial hemp? Participant 1: Um, yeah, I would probably go into it with a little more investment capital and a little bit more preparation. In terms of branding, marketing, and product creation, I have 
had little to no, um, support in those areas, I've had to do basically everything myself and as a small, family business and essentially small business, it's difficult to expand past, um, out of state categories. For example, I'd like to have a brick and mortar store accompanied with an online presence so that each basically supports the other. Uh, yes, I do plan on continuing my role with industrial hemp as a retailer, wholesaler, distributor, and consignment products business.

Interviewer: What would you advise those who are interested in supporting industrial hemp in West Virginia?

Participant 1: Uh, I would first of all suggest that you read all the rules and regulations for West Virginia Industrial Hemp, read the 2014 Farm Bill, reach out to the existing organization within West Virginia - Hemp Industries Association, West Virginia Hemp Farmer's Co-op, West Virginia University - um, look up, maybe come visit local business that actually sell hemp products so that you can get a street level perspective, and network outside of the state as well.

Interviewer: There are several end uses for industrial hemp. One of these is for use in textiles (cordage, rope, construction, clothing, etc.). What are your thoughts on using industrial hemp as a textile source?

Participant 1; I think industrial hemp is the best textile source. There's a huge, lack of infrastructure and investment capital in terms of textiles in America and/or West Virginia. Um, I do see that there's probable opportunities with some old closed down mills, uh, coal plants, or whatever, all this unused rust belt properties, if there were some seed funding, uh, business type incubator type organizations and cooperatives of people who could get together and reinvigorate that lost industry. As long as we're competing with countries like China, it's 
near impossible to recreate a textile industry. There's too many variables involved, in terms of large, uh, corporate involvement, and investment and infrastructure to make that a realistic industry opportunity. There are some niche markets there like artisan paper, textiles, and clothing that can be lucrative, but again you need some serious venture capital, investors, and a marketing/branding team. Takes a lot of money to make money. Construction, I do see probably a viable industry maybe three to five years out if we can also get the testing, certifications, and building codes all cleared out, so to speak. 


\section{Appendix B}

\section{Interview Transcriptions by Question and Answer}

\section{Knowledge Base}

\section{How did you first hear about industrial hemp?}

Mr. W. I've known about industrial hemp for probably 25 to 30 years. I used to have a clothing store that we sold hemp out of China, you know it was hemp clothing, so I knew about industrial hemp from years ago. That's where I first heard about it, you know. Mr. X. I mean, I've always been, an environmental advocate as most farmers are good stewards to the environment. I think it was in college, when I was going to WVU, studying agriculture and forestry, they had a lot of old pamphlets from the USDA. There was one from like the 30 s or 40 s that talked about the benefits of hemp and how, you know, how hemp can provide four or plus times the amount of biomass per acre than a wood plot or a forest and how beneficial it would be for, you know, deforestation and things like that.

Mr. Y. I had an undergraduate advisee about six years ago who showed up and told me that was interest as a career. Then I had a graduate student come to me for a research project and I helped her get started on that.

Mr. Z. I've known about industrial hemp for years. It wasn't until about 7 or 8 years ago that I really started learning about everything in the cannabis industry. I was able to 
differentiate between the medical, recreational and agricultural hemp. At that time, I was concentrating more on medical cannabis so whenever the industrial agricultural hemp issues came to light, I really jumped all over. I learned everything I could.

\section{Tell me about what you know of industrial hemp's growth, processing, end uses, and challenges?}

Mr. W. Last year was my first year growing industrial hemp. I was part of a nine-person trial in West Virginia, you know, so it was all under the heading of quote "research", which any hemp grown in the United States is all under the heading of "research" because they have not really made a stance on industrial hemp as a commodity crop at this point, so it's all under research, so any thing we do with it is all in research. Whether you're making oil, or whether you're making fabric, or whether you're growing for seed, or whether you're doing this or that, so under the heading of the law, it all has to be labeled under the guise of "research". So that's the first stumbling block, trying to think about, well what is industrial hemp and what can it do. So I know, um, a good bit about the growing because we've grown it and I had to grow it according to the mandate that was handed down from the Extension office out of Morgantown because they laid out how I had to plant and how I had to catalog, and how I had to observe the growing of hemp on my farm, in my climate area of West Virginia. So, other than that I the processing part, we had to learn how to process, how to harvest, but we have processed materials that we can't do anything with because there's nothing in the law that allows us to do anything with it at this point. So, I have it sitting in my barn, so we have the fiber, we have the seed, and uh, I can't sell it, because we don't have enough quantity to sell, you know what I mean, because it was such a small crop, we only did a quarter acre. So I 
couldn't grow anything in a quarter acre to make it viable, but because there's no infrastructure, I couldn't really sell it to anybody because nobody's really doing much with it and you can't cross state lines. So, basically we grew it as an experiment, as a part of the initial starting out route of getting industrial hemp, you know watching it grow and seeing if we could find ways to improve the growing of it. So, that's kind of where I'm at with the whole growth of it, I mean in just terms of looking at it in an overview and looking at it in infancy. You know, you look at Kentucky, has a thousand acres and we only have 80 acres, there's a lot of difference in it in regards to research and what you can do with growing. Mostly I was interested in growing in uh, they were supposed to be testing and I was supposed to be sending off samples to somebody, but nobody ever bother to follow up, so the whole thing for last year kind of fell through on the back end because there were no results of anybody following up on what I discovered in terms of my growing of hemp. So that information, I still have it all available, but there is nobody who has ever asked me for it. So, project, if you started something in quote "research" and you're trying to determine growing patterns, how to plant, how to harvest, what kind of yields would you get, we did everything. We measured seed, we weighed seed, we took every variety - we grew 5 varieties - so we broke it down into a pretty methodical process so that we could find out yields per variety based on the growing conditions which were three different conditions. We grew it with no soil amendments, we grew one plot with just manure, and then we used manure and blood meal in the third plot. So we grew with different mediums to see if we could influence how the way plants might grow or respond given a certain arena. So that's kind of what we did, so that's my knowledge at this point of the growing part of it and, you know, just the hands on doing it, so that's 
where we're stuck. And that's where we're stuck in West Virginia because there's no infrastructure, you know, there's no structure, there's the Farmer's Cooperative that was formed through [a founder] and through some other people in West Virginia, we're trying to really bring this forth so that it can become an agricultural crop. I'm looking at your mind map here and every use on the mind map is exactly correct, as to what could come out of industrial hemp. The only thing that's missing there, you don't have the medicinal side. You don't have the CBD oil, 'cause CBD is not technically a food it more falls into a medical arena, because it's used for pain, it's used for neurological disorders, it's used for depression, and all kinds of thing, ok. So, you might add another little box there that mentions some form of use as a medical component. Kind of falls under food, because it's ingestible, but it has a more specific, medicinal aspect. Include that in your mapping, somewhere in there.

Mr. X. Industrial hemp is a plant that has always been considered a weed mainly because it has such a capacity for growing with minimal amounts of nutrient or pesticides. It'll grow anywhere. The thing is it's been very difficult to eradicate in West Virginia even though [the commissioner], who was agricultural commissioner for many, many years, spent millions of dollars trying to eradicate - it was called ditch weed - what was the residual industrial hemp left over from the Hemp for Victory campaign that the US government had initiated, allowing the growth of industrial hemp in West Virginia and many other states during WWII. So, the residual seed that had shattered and scattered across the eastern panhandle and the Greenbrier Valley, it was just very prolific and it just very hard to eradicate. It's still found in many areas throughout those areas. As far as processing goes, since it [industrial hemp] has been banned in the United States for so 
many years, there's very little processing infrastructure here or in the rest of the United States. I think there were some that had recently been purchased by Hemp Inc. out of North Carolina and I think they have the only decorticator or commercial decorticator in the United States. There is a push by many to expand that throughout the states that have legalized industrial hemp. There are many different ways you can process industrial hemp. By decorticating it, you separate the bast from the hurd fiber and the bast - the long strands - that can be used in fabrics. The hurd is what's used in hempcrete. I'm sure you've talked about hempcrete with some of the others. It's a very diverse building material which has high insulating capacity or potential, it's somewhat waterproof and it has the ability to breathe and absorb atmospheric carbon. Then hurds can also be used for making bioplastics. They're processed out and used as an alternative to fossil fuel plastics which are very bad for the environment I'm sure you're aware of the plastic pollution we have in our streams, river, and oceans with a plastic (indiscernible) in the both northern and southern Pacific and Atlantic oceans which is an ecological disaster waiting to happen - if it hasn't already. So this has a lot of potential for creating bioplastics that are biodegradable which wouldn't mess up and have a negative impact on our environment and our ecology. There are the oils which can be pressed from the seeds and those oils can be used for biofuel, however, the wholesale value of hemp oil right now is between 20 and $40 \$$ a gallon and so, that's mainly used for cosmetics and nutritional supplements. Basically, it's because of supply and demand right now, we have to expand the market and those price will come down. That's one of the reasons that has made industrial hemp such a profitable plant and why there's been such a push because all of these different commodities that can be created from this plant. You can harvest the tops for the seed, 
which can be used for animal feed or it can be pressed for oil which you can get anywhere from 50 - 90 gallons per acre. If it’s going for $\$ 20$ a gallon, let's say you have 50 gallons, there's a thousand bucks an acre which makes it a very profitable plant just for that alone not to mention the other products that can be made from the decorticated fibers. To stay on our oil topic for a second, a farmer can buy an oil expeller for $\$ 5,000$ and make their own value added commodities and sell this. Especially if you're selling wholesale through a wholesaler, you're going to get half of what they're getting. So if it's going for $\$ 40$ a gallon on the bulk apothecary site and that's about the average price. So you'd probably get $\$ 20$ a gallon and so the farmer expels it and sells it, you're still going to get at least a thousand dollars an acre for the hempseed oil. Then the meal from pressed seed can be dried and used as animal feed or biomass for pelletized fuel. In fact, the whole plant can be chopped and pelletized and has the BTU capacity/equivalent of oak pellets. West Virginia already has a market for wood pellets for pellet burning stoves, and an acre of hemp can produce between, I think the numbers vary broadly from 3tons an acre to 10 tons an acre from what I've read. Or, we just split it down the middle and say 5 tons per acre of biomass that could be pelletized and a ton of wood pellets goes for $\$ 230$ a ton. So there's another thousand dollars' worth of value added commodities that can be produced if the farmer could buy or lease a pelletizer. And that's one of the things when I started the Hemp Farmer's Cooperative, which is now considered the WV Farmer's Cooperative. We've renamed ourselves so we don't restrict ourselves just to hemp. There's two commodities and then you have the potential with climate change to sequester the carbon in the soils. I read where 1.3 tons of carbon can be sequestered in the soil for every ton of biomass produced above ground and so that could be a commodity if 
they ever start a carbon market where there's carbon trading sales. So there's different, unlimited possibilities with the production, processing, and sale of industrial hemp. Mr. Y. So, we have one year of field experience now, so I have that in respect to its growth. The processing, I don't have any firsthand experience, except what I've read, same with end uses. Challenges, there's a lot. In terms of growth, it's an annual, grows very rapidly. This year, we had some problems with it going to flower earlier than we expected, so it kind of caught us off guard on our harvesting. So, processing, I know they use both the fiber and grain. The fiber has excessive processing, that I'm only casually familiar with. End uses, paper, the fiber makes excellent textiles, can be used in building products and plastic substitutes. The challenges are immense right now. There are no good ways to harvest, we don't have the infrastructure here. The fiber harvesting, that's kind of just a mowing and baling, but there's nowhere to take it. There's a lot of agronomic factors we don't know about right now on how to process it.

So, in terms of the industry progressing, we have to do something about an end uses for this. I have a lot of people tell me they want to get a permit to grow industrial hemp and their net question is, what am I going to do with it at the end of the season, and I don't know about that one. So, I hope places like Hemp Farmer's Cooperative are working on those kinds of things. I've encouraged them to, I don't know how well they've followed up on that. I can't even recommend to people, you now, basic agronomic practices, even what varieties to select, how to fertilize it, what are optimal PHs, just the standard things we know for any crop you might want to grow in the state. We have some base of information to tell people, but this is so new that we're really at a loss. 
Mr. Z. Actually, I know a good bit about it. I'm running a lot of the industrial, well, the entire cannabis industry in the state. I do know we have an opportunity to utilize industrial agricultural hemp to diversify our state's economy and the numbers that I am seeing and that I am trying to generate are phenomenal. It will really be an economic boost to our state. Not so much in the growing, but the processing of it, the industrialization, the manufacturing, downstream products. So that's where West Virginia is really uniquely situated. There are thousands of end uses for the entire cannabis - the agricultural industrial hemp, we seem to be segmenting the industry into several different avenues. One of the first and easiest things we hope to do is harvest the seed and either de-hull, or press those seed for oil. If we de-hull, we can use them for food. You can buy hulled hemp seeds in many store and online right now. The oil is one of the best nutritional supplements you can get and just so many purposes. Another oil we will be extracting is the CBD oils and that's where the real gold mine is at this time. So, that takes care of pretty much the tops of the plant. We have yet to get down to the actual fiber of this plant or even the leaves. We're going to knock this down even more We can use the fibers for a textile industry that we're working on, a paper industry we're working on, even a toilet paper industry of all things that we're working on in this state. Whenever we break it on down into [indiscernible] artesian paper, even copy paper, hemp paper has quite a few superior characteristics to your wood pulp paper. So, we'll be able to take that into cardboard, copy paper, even artesian paper, on and on and on. Another interesting use of course was the textile industry and we have found through our research your hemp textiles are very, very long lasting, antimicrobial, UV radiation resistant, many, many, attributes to it. It is a very comfortable fiber and very robust It will last a long time. As 
we move down further for the end uses in this state, it has some high-tech end uses that we're working on. I'm running a company called [name removed] and it's a very high tech application for our hemp use. We will be making graphene from hemp. Graphene is a single layer of carbon atoms and it is quite handy in advanced battery technologies. A couple more uses that we will be working on from the leftover fibers is activated charcoal. It appears that hemp produces a superior grade of activated charcoal a lot more surface area, exactly like the graphene, that's why it works out so good with hemp, there's a lot more surface area. We're going into hemp plastics, the bioplastics market. So, the downstream application of hemp is everywhere between food, medicine, food, and fiber and these fiber uses are just not for making rope and canvas anymore, we're going into a multitude of high-tech applications from the plant. It's just an incredible opportunity to capitalize on the entire plant and derive many different uses and income streams from a single stalk of hemp. Well, the challenges are vast. Number one being politics, the politics of getting into this business is very prohibitive, it's still considered a controlled substance. From that, the full industrialization of the plant is being held back. Another challenge of the industry, of course, is finance We have run into one obstacle after the next financing industrial hemp projects. I am sure that they are not so concerned about people getting high on the other cannabis products for recreational and medical cannabis, they obviously do not want to face the competition that hemp brings to the market place. I could take a couple million dollars and go to a free state, like California, Oregon, Washington, or Colorado and open up a grow facility and grow some of the strongest cannabis on the planet, you know, just real cannabis, but if I were to put in a thousand-acre field of hemp and put a factory at the bottom of the hill, I'd be in trouble, 
there would be big trouble. That's exactly what we're facing right now. We're making progress, but it's a long way from being a properly regulated and managed marketplace.

\section{Which of those stood out to you the most as being a key piece you wanted to know more about?}

Mr. W. My personal choice was to grow high CBD, you know, for the medicinal trade. That's what I was really interested in, so the growing is not that hard, you know, you plant a seed, you watch it grow. So, the end uses are what I would be more interested in, is what can we do with the material once it's grown. Because you have to create the marketplace. If you don't have a marketplace, how to you have a commodity to sell? So you have to create the marketplace, which, in America, the marketplace is already there. The marketplace for every one of your categories is already in existence, but we're importing in those products from other countries like India and China, ok? So the problem is, if we're going to establish a commodity in the United States that growers and farmers can grow as something they can make money on, they're going to look at the detail of the infrastructure so that these people would quit buying overseas a hemp product that could be manufactured here. You know, most hemp coming to the country is already manufactured. So that means it's grown somewhere else, of course it's manufacture somewhere else, there's no real economic gain other than a retailer buying a hemp made shirt and putting it on a rack and selling it. We want to take it back now and say "wait a minute". I think we can become a leader in hemp production in the world, competing against India and China, but because the infrastructure is not really allowing 
us to do that at this point, we kind of have to do our research, growing and getting the infrastructure put into place and that's the challenge right now. So, end use is what I'm interested in because I got to grow CBD hemp and actually be able to extract it with the viability that it could be used in medicinal form. You know, so people could use it as a medical benefit.

Mr. X. No, I'm the type of person that really delves into something and wants to know everything about the possibilities. So I don't think anything stood out more than, well, I had mentioned when I had first learned about the potentials and benefits from of industrial hemp while I was in college from the USDA flier that where it could reduce the need for deforestation by producing 4 times the amount of biomass or fiber per acre and I did see that as a way to reduce deforestation and improve our ecology and our environment. So, I'd say that was the key piece that stood out that I wanted to know more about it and delved me into research and understanding the plant a little better.

Mr. Y. So, the undergraduate student asked me to help outline a research project to help him get started. Basically, what I suggested, was to keep it simple and try to get some growers around to state to cooperate with varieties [indiscernible]. After he graduated, he never followed up on that [indiscernible] when the graduate student came along, I suggested we see what we could do with that and she had talks with the cooperative and there were some people who were interested in helping with that and so that's how we got started. We didn't have any money for her and I paid for the seed, which is still fairly expensive, out of my own overhead money. I didn't have any way to pay her and so many of the growers seemed to - I'm not disparaging anybody - I think they just wanted their seed and wanted to do what they wanted with it. They weren't really engaged in 
combining information to make best practices that kind of thing. We kind of lost control with what the other producers were doing. We're hoping to keep better control of that this year.

Mr. Z. Well, for me personally, I would have to say it would be the CBD oil part of this. My wife has Multiple Sclerosis (MS) and they have done some research where there is a cultivar of cannabis, you can call it hemp or medical it doesn't make a difference, but it has like a $2 \%$ THC rating and a 20\% CBD rating and it has been getting some glowing results from MS patients. On the other side of it, I think the advanced battery technologies that we're getting into is an intensely interesting objective to me personally. Years and years ago I was in the electronics industry and I know just enough about electronics and batteries, and power supplies and production that this new technology, to me, is one of the turning points in the history of the industrial revolution. When we bring these advanced batteries to market, it's going to be a game changer in power production and energy storage in the world. So we're looking quite forward to that.

\section{Involvement and Support}

\section{Once you were interested in industrial hemp, how did you become involved?}

Mr. W. Ok, I got interested last year, uh, when I was approached by [a founder of WV Farmer's Cooperative] about my interest in hemp, because I'd met him and he'd said, "hey, I'm trying to get this hemp thing going if you'd be interested in being a [indiscernible]", and he was talking about what he was doing and I said, "oh yeah, I'd love to get involved". So that's when I went through all the stepping stones to be licensed in the state of West Virginia. I was one of 9 growers licensed legally to be able to grow 
industrial hemp. Had to go through the FBI, had to register with the DEA, you know, had to go through all the hoops to make it happen. So, that's how I started to get involved was because I was introduced to it and I said, "hey, I got land. I can grow that." It just seemed perfect because, you know, I'm a herbalist and an organic farmer I thought, well, I'd look at it from two sides; growing it for either food, medicinal, essential fatty acid, or whether I'm growing it for CBD. So I wasn't really interested in fiber for clothing, but because you can use every piece of the plant, to me, even though you're growing for feed production, or let's say for oil production, or let's say for CBD, you're always going to have a stalk. It can still be processed, so every piece of the plant can be used no matter what. Whether you're growing ten acres or a 100 acres, what are you going to do with your raw materials after it's harvested and what parts I want, what's going to happen to the fiber? I'm going to sell it, so it's pretty cool how it all works.

Mr. X. Well, I used to be a, while I still am, a member of the Sierra Club, but I used to be on the executive committee of the Sierra Club while I lived in Morgantown and you know we discussed that and what it would take to legalize industrial hemp and that's before I even considered getting into politics. When I got involved in politics, it was because I'm involved in more than 10 nonprofits that deal with social and well as environmental issues and the reasoning was because I was tired of banging my head against the wall from the outside trying to get the existing legislators to change policies and I figured it you can't beat them, join them. It took me three tries before I won election in an area I am not a native of and everyone said, "you'll never get elected because you're not a $10^{\text {th }}$ generation (name erased) Countian". And so, that's one of the things, I got involved in the community, I was already involved on some of the 
nonprofits, and so it just seemed like the right thing to do and it helped the community I got a name made for myself helping with different nonprofits and organizations where people got to know me, like me and I was in office for 6 years.

Mr. Y. So, I worked [indiscernible] had the contracts, had to get licensed, the FBI, State Police background checks, and then we had to work with WVU Legal Counsel to work with the seed companies in what they call Material Transfer Agreement for them to transfer seed to us and so there's a lot of what you might call red tape just to get started. And she did most of it and did excellent with it. I only had to participate in a few meetings, phone calls, read a few licensing agreements, but she did most of it. I don't know if she [graduate student] had to go through the background checks. I assume so, but I don't know and she's not working with me anymore.

Mr. Z. That's a very good question. Early on with my advocacy for alternative agriculture, I started with bamboo. I wanted to put bamboo plantation on strip mines throughout Appalachia. The coal industry was at first interested and then they were not interested and when they started the Obama war on coal, we were left in the weeds on that. When my wife was diagnosed with MS, I started working on medical cannabis with a delegate, this makes year 7 that I have worked on this. When the agricultural hemp issue came up, I had unique qualifications to get on point with this industry. I have put tens of thousands of bales of hay in the barn as a sharecropper, kind of a high speed sharecropper, but my veteran agricultural thing did not work at that time, so I found a job in sales of all things, that's the only thing I could find any kind of work in. Well, I got pretty good at it and eventually, I worked my way to an executive level position where I had my company's corporate jet anytime I wanted it. So, yeah I have put together many 
multi-million deals in the back of an airplane. So, that kind of left me uniquely qualified to ramrod this industry. Sure, enough, we got it. They almost stopped us last year with Senate Bill 159 which was a Rules bundle and one of those rules took out the individual farmer and industrial agriculture hemp test plots. So, we were dead in the water, right around planting season, and the governor was convinced by one individual, to veto Senate 159 and we went from dead in the water to throttles on the firewall overnight and we made history by getting 9 farmers to plant industrial agricultural hemp here in West Virginia for the first time wince WWII. So, it is a very interesting problem and now we're to a point where we are doubling the number of farmers and tripling the amount of acreage we have in production. So, I'm quite proud of everybody who has joined in on the effort and made these accomplishments.

\section{What can you tell us about the steps you took to pursue this area you are involved in?}

Mr. W. Ok, the steps. I kind of gave you some of the steps. You have to apply to the state of West Virginia to the Department of Agriculture, for what was called a Provisional Hemp Permit. The provisional permit was based on the fact that I could get started as long as I met the requirements of the FBI background, police background checks, ok, and all those kind of requirements because there were specific requirements that had to be made. And I have my certificate up on the wall, I got my new one for this year so I can continue to grow. So it is a licensed procedure you have to go through to be able to do it. And they don't give licenses to everybody. I ended up talking to the gentleman in the [indiscernible] uh, the Department of Agriculture the state of West Virginia, had a very detailed conversation and he came out to my farm and he inspected my farm to see that I was a viable and the interest that I had in hemp was going to benefit 
the Department of Agriculture from the state of West Virginia. Ok, so it tied it in also back to the university extension, the Ag extension, because that was who was going to work the details of who was going to do it, but yet we still had to have the approval from the Department of Ag, from the state level. Lot of bureaucratic stuff you have to deal with.

Mr. X. Initially I started pushing for that change in policy to legalize it on the state level even though it was illegal federally. With the movement across the country of medical marijuana, recreational marijuana, hemp was getting more traction and eventually - and I had introduced the bill every year I was in office all six years - to remove hemp from the Schedule 1 category on the state level. Which would have opened it for growth and production by farmers in West Virginia. And then in 2014, which was my last year in office, the United State Congress passed the Farm Bill which said that states with a legal industrial hemp program could grow it and process it for research. And so, I was already, and other people, were already supportive of it, because I have been such an advocate those six years in office that it pretty much went straight through committee and passed without any glitches. And so, in 2015, even though I was removed from office because I lost the election, they still had to process what is called the rules, and the rules are how it is governed even though it's legalized, it's how it is regulated and governed by the state. And so the Department of Agriculture, we worked with them [a professor] at WVU and I and some of [the professor's] students got together and worked on developing those rules for the Department of Agriculture and pretty much - there were a few changes - but for the most part, the rules stood strong and we got them passed. Then in 2016, I was one of the first permanent to grow industrial hemp for research in West Virginia. In fact, I am 
the first hemp farmer to run for Congress since Thomas Jefferson. I ran for Congress this past election and that was part of my campaign platform. And you know, I kind of took pride in that, I thought it was pretty cool.

Mr. Y. I am affiliated with West Virginia University, I'm a professor. I am trying to get external money to continue the work that we started and I have several colleagues who are interested on working on various end uses of the product once we get it harvested, including organized products and [indiscernible] quality, things like that. We, because we are a university, we cannot be a member of the Hemp Farmer's Cooperative, but I support them to the extent I understand them, I am supportive of their efforts. I could be part of them as a private citizen, I think, but I've heard that this year it's quite expensive to join, so I'm going to decline that opportunity. I am also involved, as an investigator, on a regional project for industrial hemp that includes four, five states in our regional area.

Mr. Z. There was a strange force, if you call it that, of serendipity. It's been amazing, the phone calls and connects that have enhanced the overall industry. Out of the blue, people would call and be talking about one thing or another and it would go into ag hemp and then they would find out who I was, what I was doing in ag hemp and it would take us into have one avenue of opportunities after another and more and more people have joined in. Things just come out of the blue, completely unexpected. The steps have been enhanced by just sheer coincident serendipity.

\section{Currently, what is your affiliation, role, or association with industrial hemp?}

Mr. W. I am a founding member of the, what is now called the West Virginia Farmer's Cooperative. It used to be the West Virginia Hemp Grower's Cooperative, now the name changed just this month. So we're a different kind of cooperative, because we can grow 
other things besides hemp. The idea is to grow other diverse crops in the state of West Virginia, but because hemp is our primary crop, we didn't want hemp in the name because it would limit us only to hemp and we wanted to be broader, 'cause there might be other things we want to raise. So, I am a member, I am a vested member, and I am on the board of directors with the West Virginia Farmer's Cooperative.

Mr. Y. Well, I am one of the cofounders and vice president, and co-directors of the West Virginia Hemp Farmer's Cooperative, which as I said earlier, we have changed to the West Virginia Farmer's Cooperative. We are working with state legislature to reduce some of the restrictions on growing industrial hemp, because now you have to have an FBI background check, a state police background check, you have to be fingerprinted, pay all these fees, and it shouldn't be that way, because it's not something that people are going to get high on. The amount of THC in it, which is relatively low, is so low, that it would take several wheelbarrows full if not a pickup truck load to get high and they'd die of smoke inhalation first before they even got close. West Virginia is very [indiscernible], in my bill, I had put a THC content of $1 \%$, just because I thought we'd need a little bit of wiggle room just because I didn't know how easy or hard it would be to get certified seed that had that $.3 \%$ THC level. With the onset of medical oils, cannabinoids, cannabinoid oils, and the increased demand for that, well, when we got the rules passed, as the statues read we could grow industrial hemp with THC of $1 \%$ or .3\% as the, I'm trying to remember exactly, basically it's $1 \%$ or $.3 \%$ as indicated by the federal statue, I guess. Or whichever is more restrictive. We tried to remove that language from the rules, because other states have higher levels of THC and medical marijuana and still the 1\% is enough that it wouldn't get people high, but would still have the medical benefits if we were to 
extract the oils and use that in some of our value added commodities. Because that's one thing we didn't talk about in processing and end uses is the medical qualities and demand for those oils which can be extracted from the flower heads after the seeds have been shattered So once the seed has been shattered, you have the tops, which hold all the cannabinoid oils. See, there's different oils, you have seed oils and you have plant oils and the cannabinoids can be extracted through a super critical $\mathrm{CO} 2$ extraction process or using petrochemicals and its much safer and more cost effective using the $\mathrm{CO} 2$ extraction because you don't have those toxins and residuals in the oils you extract, which would be used for human consumption.

Mr. Z. I'm part owner of the West Virginia Hemp Farmer's Cooperative, I own \{company] outright and part owner and CEO of [another company]. Other affiliations, I am dealing with the Hemp Industries Association and a variety of just other business interests where I advise on various levels of agriculture, but including industrial ag hemp.

\section{What was the reaction from those around you when you expressed interested and became involved?}

Mr. W. Actually, you know, the reactions were mostly positive. Of course, jokingly,

“Oh, you gonna smoke that stuff?" you know, so people have the misconception of looking at hemp versus marijuana even though it's basically the same plant, when we talk in reference to hemp, we know it's cannabis, but it's cannabis with no THC, so you know there's always the follow-up line which is, "well, you know, there is no THC in this and this is not a get high plant, this is an industrial plant for use in industry". So the initial reaction was always kind of joking at first, but then once I started to explain, everybody really got on board and said, "Oh yeah. That really makes a lot of sense”. And so they've 
gotten to be very supportive of that. And I've had people, because I was in the newspaper and because of interviews, because of this whole thing, and because of my nature in my community, a lot of people know me, so we go out to dinner and people say, "Oh so, you know about the hemp thing. That's pretty cool." Of course I have a sticker on my truck that says "I grow hemp", you know that type of thing. So, I'm proud of it. We need this. The state of West Virginia needs this, so I think it's good.

Mr. X. Ah...it'll never pass. Because I was also the first person to introduce a medical cannabis bill, or high THC marijuana, and so once I got involved in the hemp I saw how the cannabis revolution had taken hold across the country, I think 12 states at the time. I had no idea at the time that medical marijuana was even legal in other states. As I did my research and got involved to pass legislation for that, I got more flack for the medical marijuana bill than I did for industrial hemp. I did my research and also got involved working on getting legislation passed for that. And so, I got more flak from the medical marijuana than hemp.

Mr. Y. So, I am a soil scientist, the interest was really, is this a potential alternative for biomass fuel production, could it reclaim disturbed soils, does it have nitro[indiscernible] potential? Really, an agronomist should be leading this, classically trained in growing [indiscernible] crop production, or something like that. An agronomist is not that interested in hemp as a project and I'm not sure why.

Mr. Z. It just depends on the individual. Some people were just shocked. Some people who know me, well a lot of people, it's just been shocking that, I've had the guts to go out and do something, because they see the SWAT team videos on YouTube, they hear of people being busted and their property being seized. Not too many want to put their 
freedom or their properties at that kind of risk and I can't blame them at all. I've been able to pull it off without having been busted or any properties seized. On the other side, a funny thing is happening. Since we won the battle with Senate Bill 159, my political star seems to be shinning even more, I was not expecting that. People respect the business angle of this thing more now and they see me and my business associated as a hopeful force to be dealt with. They hope we can succeed and bring new industry, new entrepreneurial opportunity, new jobs, to the state. So, that part, it did not blow up in my face yet.

\section{What types of help and support have you found in the community of industrial hemp growers, politicians, and others?}

Mr. W. Grower's support? Yes, most definitely. I have many politicians who came up to me, because it was an election year, who said, "we think West Virginia should make industrial hemp legal", and also it brought up the question of medical marijuana. Most of the legislators I talked to were in agreement that medical marijuana did have a place and should be legal in West Virginia and that's something that will be tackled in the next few years of legislature and I think will be that medical marijuana will get approved as well as the fact that the new Department of Ag head coming in this year is also pro hemp. So I think that means it's going to open up many, many doorways and many opportunities for farmers and other people to get into growing hemp as well as we can get the infrastructure into place. I think it's very exciting. I think there's a lot of buzz around it, so, I think it's good! It's a positive thing.

Mr. X. Well, it's very amazing and it was very surprising as to how many of the legislators and people in the community have embraced industrial hemp. Because, I 
believe, that since medical marijuana had come into the scene nationwide with so much exposure in the press, industrial hemp, which is sort of like a cousin to the marijuana was getting similar exposure and people understood, not everyone, that it was ridiculous to even have it illegal because people can't get high on it. My argument with law enforcement was if you let us to plant and cross pollinate, if people grow industrial hemp outside, a marijuana crop within a two-mile radius of that hemp crop, it would cross pollinate and ruin the marijuana crop, essentially turning it into industrial hemp and people couldn't get high off of it. But you know, their argument was "it looks like marijuana and if you plant marijuana with it, it will disguise it". I'm like, you can disguise, but hemp is going to disguise it to the end user and they can't get high. So it was hard getting them to understand, but it's all a learning process, but I think most law enforcement has come to terms and understand it now.

Mr. Y. Everyone else has been really supportive, especially once doing the homework and getting the seed was done. [The grad student] was featured in a couple of reports that got picked up and all of a sudden they are contacting me saying, we want to do this or that, and I'm like, where were you six months ago. They've continued to be engaged, but, it's very hard for me to do anything because I don't have any money to give them. Anything to with research needs to be externally funded. What I have to caution myself about is that, and this is part of the reason I have chosen not to join the cooperative, is that most cooperatives that I'm familiar with have a research focus. This group has an interest in advocacy and as a university employee, I try very hard not to advocate for one thing or another, but to simply give advice, to transmit knowledge. Sometimes I have trouble walking that line with the cooperative. I don't know any other hemp growers 
although I met some for this year last week. Within my own university, they have been very supportive. My associate dean for research has been extremely helpful and supportive, the Legal Counsel has been shockingly helpful. We usually think of lawyers as being obstructionists, but they have been anything but that. Within my own institution, I think it's good. I suspect, I hope, that as more growers get involved they will contact the university and I'll make their acquaintance. They ask me questions sometimes and I don't have answers for them, so that's awkward for me.

Mr. Z. Again, that started off with nothing by ice cold and it has been one obstruction after the next. Many of them see us as outlaws, hippies wanting to get high -and include the word biker hippie in that for me. Over a period of time, the more enlightened people saw exactly what we were doing and they see exactly what's going on in the world, over a period of time that message has become more and more positive. The support is just growing. It's incredible, we're no longer a bunch of hippies wanting to get high, we're agricultural and sustainable industrialists and entrepreneurs. So, now all of a sudden, we have a whole new respect for what's going on and what we're doing. At this time, I've been to the Farm Conference this past week, I've been to the capitol, the optimism is guarded, but there is optimism now and there a lot of people who do not want their fingerprints on this because it is a political hot potato. We're relentless on what we're

doing and we are making progress. In a state that is as financially strapped and backwards as we ware, the enlightened people see us as the somebody who is actually championing the best interest of the state and others see us as the devil.

\section{Tell me about your involvement with any of the known industrial hemp organizations in West Virginia?}


Mr. W. There are some other organizations I am not actively involved in because I've put all my work into working with the West Virginia Farmer's Cooperative. Mainly, there's just so much, I can't be diversified in so many places. There are some other organizations that the Farmer's Cooperative will be involved in throughout the state and we already are partnering with some of them, but I'm not quite the king pin on that. Mr. X. Yeah, the WVHFC.

Mr. Y. I have not been involved, personally, with any of them.

Mr. Z. Well, that is an interesting question. There are a variety of national organization, like, again, the Hemp Industries Association, we have the West Virginia Hemp Industries Association, and then we have, of course, our cooperative, the West Virginia Hemp Farmer's Cooperative, which is doing business as the West Virginia Farmer's Cooperative. The real interesting thing about the national organizations, they were not really around here too much to help out. They're estimates were very low for West Virginia, so they didn't spend resources coming here, they went to states where they thought they had more chance getting legislation passed. So, these organizations are fine and dandy, dearly love them, don't get me wrong, but when it comes to the organization that are developing industrial Ag hemp in West Virginia, you're talking to them.

\section{Future of Industrial Hemp in West Virginia}

\section{Where do you see industrial hemp going in the future within West Virginia?}

Mr. W. I think there's great future, the real point, you know, is getting everybody on the same page. You have to get the legislature, you have to get the education, you have to get the Department of Ag, all those have to come together and we have to develop an 
infrastructure so that if more farmers wanted to grow hemp, they would have the vehicle to be able to do so. But, you also then have to work on; are we going to be a processor, do we have processing in the state of West Virginia, or do we have to ship everything to Kentucky? Or to another state that would have processing? See? So why grow something if you can't sell it? So that's the challenge we have is that the infrastructure needs to be developed amongst then, that's the legislative action and the Department of Ag, working to help to lay down a plan so that it makes it possible to have it. I think there is a real place for it, we have a lot of land in West Virginia, we have a lot of farmers who are just doing cattle, they're raising corn and maybe some soy beans, and the diversity of the crop could be so much greater. So that's the problem, the diversity, we need more diversity, and I don't know why they don't just go back to 1935 when they were growing it and the U.S. government made it legal to grow hemp and all you have to do is go back in the history and re-set up what was already in existence, because it was already being done. All we're going to do is regenerate it and refresh it. So why wouldn't you go back to the model that you previously had and see if you couldn't re-implement that model or some variance of that model? And I've already told this to the Department of Ag, I've told this to the people in charge I said, "why recreate the wheel when it's already been done?". All we have to do is go back, drag it out and review it, and see what needs to be changed to make it current to the current times that we're in right now. So, anyway, we'll see what happens.

- Mr. X. Well, we are working with a nonprofit out of NYC right now, because they had been following my political career, which surprised me that I was being noticed outside of the state. They had made a proposal, which they are still working on with their 
attorneys, they are going to try and bring in up to 50 million dollars in research and development grant money to develop the industry in WV. What we hope to do is to be able to develop the [indiscernible] industry using industrial hemp. So it would increase demand so farmers would grow it, we are limited on land because of our hills, but we can still grow it in many areas, but would benefit us the most, since we are in the Ohio River valley, we could have hemp barge pier from numerous other states, OH, PA, NY, KY, and beyond, if we were to have the infrastructure to have commercial processing plants here for job creation.

Mr. Y. So, it is very fast growing. It is a prolific seed producer. There is, because it is an industrial crop, it has the potential to expand, or build on our existing industrial capacity, especially some of our plastic products, or even the pharmaceuticals that it can be used for. Some of the building products, I have a colleague in Wood Science and I think he has an interest in some of those, so we'll be doing some unfunded, preliminary projects on that. You know, this sort of complements our existing forestry base.

Mr. Z. Well, I was on a conference a week and a half ago with operators out of Kentucky and North Carolina, we're forging alliances with other hemp operators on the eastern seaboard. I'll give you an example; state of KY right now is running 13 thousand acres per minute for this year's crop. State of NC crop is going to be 1200 acres, right now we're 30 acres, here in WV. I told these guys that I fully realize we cannot outgrow the flatlanders. We can grow some of the best cannabis in the world right here, we're in a sweet spot for growing cannabis, but we don't have the flat land to really make the huge, effective crops that we're going to be needing for our industry. 


\section{Where would you like to see industrial hemp go in West Virginia? What is your vision that you have for this crop in this state?}

Mr. W. I would love to become a huge money making crop for all of West Virginia. I'd like it to become a commodity that is something any farmer who wanted to grow it, could grow it. Without having to go through a ton of - the stigma of having to go through FBI checks, because it's a scheduled drug - is the DEA changes its classification on all hemp and that will also change and make it easier for someone to grow it. Because the DEA had all hemp and cannabis as Schedule 1 and that makes it very prohibited even though this has no THC in it. So that means the person who just wants to grow hemp, can just go out and grow it without - because you can't get the seed and you got to be licensed. So, you know, it's ok to start out that way, but if you're looking five years, ten years down the road, for a real viable, economic crop, you're going to have to relax the standards so that people can get into it, otherwise they won't do it. You got to make it affordable for people. You got to make it so they can do that and can afford to.

Mr. X. That's really what I see as the silver lining in this whole thing is that we have the potential especially if any of this grant money come to fruition is that we can develop the infrastructure needed to attract bringing industrial hemp grown in other states to be processed here so we could create jobs in the processing of industrial hemp, whether through decortication and we have the Polymer Alliance zone -right down the Ohio River valley which I believe expands through Wood county down through Jackson county numerous companies producing plastics and they are being hit hard by offshoring and imports from China and so they are struggling to survive now and the increased demand in bioplastics, I think this is the next step for those industries to be able to survive. The 
demand for bioplastics is increasing because of people's awareness of the amount of pollutants we're putting in causing the plastic contamination of our streams and oceans. As I said, we already have an established industry for wood pellets in, in Preston County, one of the biggest wood pellets, I think Allegheny Wood Industries. They produce, I think, a million tons of wood pellets a year, but you know, here's the farmers who could or the cooperative - could purchase a pelletizer and help or members could lease to farmers and could pelletize their industrial hemp, bag it, and sell it for value added commodities and sell locally. We have the oils, I can see the cooperative buying an oil dispeller, or a farmer, and an acre could pay for that expeller in one season. So, then they would have that to use for value added commodities, producing the oils and then the, but anyways. I start rambling. Job creation, for building the infrastructure processing, to craft the agriculture producers to ship here and process, we're within half of the population, 4 hours of half the population of the country, so many states around us have more tillable land that we do, and it would be helpful in helping us to diversify our economy to build it, make the state more attractive, and less people would be leaving if we had a greener economy rather than just focusing on the attraction industries in WV.

Mr. Y. It has potential, yet I hesitate to tell people to invest in a very expensive seed and take their hand out of other production and don't know where to sell it. There's no way to sell it, so why are you going to invest 1,000 dollars or more in seed and maybe not even cover it. I paid 1,800 dollars last year for five varieties and we still have some left over. If you are planting one variety on an acre, you'd be looking at about 600-800 dollars. We're going to start some experiments, I hope, with an undergraduate, on is it able to take up metals from metal contaminated soils. So, I think it likely has some potential in 
reclaiming brown fields, putting organic matter in reclaimed mine sites. We always have a problem with those because there is no way to get any value out of planting switch grass or willows or something like that, we hope there is, but if we can create a market for industrial hemp it would really change the game with respect to making reclaimed mine soils productive from an economic standpoint again. So, that would be awesome. A lot of piece have to fall in place and one of the challenges on doing this research is that it looks just like the one that's used for fun, it smells like it. So, when you think about planning it on reclaimed sites we can't fence or control, until it becomes, you don't want to spend a lot of money out of your own pocket and then come back to harvest and someone thought it was there for fun and you have nothing left. Your whole experiment is gone and it's a waste of resources. So, that, for me, is sort of a hurdle that needs to be overcome as well. I think it, based on last years' experience and the literature, it does have potential in brown field developments.

Mr. Z. The future for WV hemp industry is the development of factories, mills, and refineries. I told these operators that we have a lot of idle industrial space around this state. What we're going to do here is develop those to process this agricultural hemp into value added products. I'll be buying their hemp and processing it here, we'll be growing a good bit of our own, but I see this industry as so large that we won't be able to meet the demand for feedstock and our local agriculture. I'll have to buy hemp from the flatlanders who have tens of thousands of acres to process for our value added products. Two of the factories on the drawing board right now one will require 13,000 acres of hemp per year. The other one is looking like 7,500 per year and it could possibly triple on this other one. So, hemp operation, trying to get 20,000 acres of hemp production put together in this 
state's going to be difficult but not as difficult as the flatland farmers. We'll be growing here, don't get me wrong, but to get the feedstock for our proposed factories, mills, and refineries, I'm going to need to buy hemp off of other people. But, that's our future, we're the manufacturers. We're an eight-hour drive from $63+\%$ of the population and we're not that far out of the ports of Cleveland, Baltimore, and Norfolk, so international sales of our value added products are not out of the question. I'll be hiring and developing a sales force to get these products quickly out to market. The way I see it, we'll be screaming for more hemp to feed these factories, mills, and refineries, the demand and the output of these new value added products, are sustainable, this entire industry is sustainable and this industry cannot really be offshored. So, hopefully, the things were developing now will be in full production shortly, as soon as possible, but the real trick to it, is that these industries should be here indefinitely. It's really looking very hopeful.

\section{Anything you would do over again or change about your experience with industrial hemp? Will you plan on continuing in the role you now take in industrial hemp?}

Mr. W. Last year was totally a [indiscernible] year. We thought we were going to get guidance from the university. We had a person there at the university that was supposed to be our point guard. He was supposed to be coming in, inspecting our facilities, supposed to help us in our planting, our harvesting, he was supposed to help take sample and do things with it. And that never happened. Never happened. I had one farm visit and I was left alone on my own to do whatever I chose to do. So the disconnect is, the person who was in charge dropped the ball, dropped out of the program, and nobody came to fill the spot which left me, as the experimental farmer, not having any direction whatsoever, 
so we took the bull by the horns and we did our own research and our own thing based on no guidance whatsoever, but based on a methodical process that made sense to us. So, if I had to look back, it would have been nice to have the infrastructure in place so that as a new farmer growing hemp, they would have had someone giving you advice as opposed to, "Well, we don't know what's going on, just go whatever you do". So you see and we're only one year in. It's a little bit of a criticism for sure, but it's also an indicator of the deficiency of infrastructure that's not in place. So, if you're going to make this happen, and the real point I would stress in whatever you're writing, is that the development process has to move forward. And it does have to move forward rather quickly. Within this year, we should be able to get things to the point where by next year, this year they opened it up to 20 farmers, instead of 9 . So now we have a bigger group of farmers who are going to be able to grow, with the idea that next year there could be 50 and 100 the next and with each person growing we can say, "ok is it going to be an acre, is it going to be 5 acres, is it going to be 10 acres?" because if you're talking like Kentucky with 4,000 acres, under production, and here we are, 8 acres under production, how can you make anything viable? So, the thing is, they're further along. Why don't we work with Kentucky, look at their infrastructure and maybe adopt some of their things? Because right now, you're not technically allowed to carry a hemp product across state lines. The federal regulations, see? So the federal regulations have to change, the states then could adopt a looser policy, and then it can trickle into where we can have an expert - people in our Ag department and educational department and the university side - that can actually guide and direct and give people the guidance that they need. Because it was totally fly by the seat of your pants last year. 
Mr. X. There's nothing I would change. Once I start something, I work on it until I bring it to fruition. It's not to the point I'd like to see it and I'll continue working as long as it takes to help develop this industry in the state.

Mr. Y. I think I would have tried to insist more strongly that they grower participants follow the experimental protocols and then follow up with them. That was largely a disaster. The problem is they've got their own agendas and reasons for wanting to do this and have mixed experiences and attach value to land grant university missions, so basically they volunteer to help out of the goodness of their hearts. Our state does not have they requirement that they have to work with the university as some other states do. That's how they were able to kind of go and do their own things. So that's one of my hurdles. They don't have to be associated with me to get hemp seed or do research. It's just a peculiar way our Department of Agriculture wrote the rule. I didn't see the permits, so I assume they are taking advantage of the DoA's rule that they are a pilot program doing independent research. I say that's what I would have liked to have done, but without the resources in place, it was impossible. I guess I would like to see the resources in place so that it is more likely to succeed than not. There are 22 permit holders for this year. I don't know, I know one of them because I bumped into them. That is completely different than other states when the university organizes the research and they cooperate with the university. They may think they are cooperating with us, but I'm not aware that they are.

So, I will make a concerted effort over the next year to get external funding and if I can, then I can continue our research program. If I can't, it will probably limp along, may or may not include me, just depends. 
Mr. Z. I cannot think of anything that I would change myself. We have done this on a shoestring budget. Most of what we've done has been paid for out of our own pockets and it's hard to tell how much money and time I have invested in this entire project. Whenever you're operating like that, it's hard to look back and think you should have done anything different when you have no money. So, you know, whenever you operate on a shoe string like that, there's very few alternatives you have. Now, if I had piles of money going into this, if I'd have done anything differently, I'd have been all over the state, and all over the county, and all over the world learning more and more about how they're doing agricultural hemp. In many countries, it's already legal and they are in full production. I'd have been eyes on their operations and been there talking to the people who manage their industries. That'd be the only thing I'd do differently if I'd had money. Not having money though, there isn't anything I could have done differently. Absolutely, I'm in my 60s and I'm trying to get this off the board and turned over to younger people as quickly and I can go. The young people I am dealing with right now have been outstanding in running the ball. If I see something that they can do, I do not micromanage them. I share with them the vision, I listen to their visions and together we collaborate on what an ideal situation is going to look like, I throw them the ball and they run.

\section{What would you advise those who are interested in supporting industrial hemp in West Virginia?}

Mr. W. I would say, learn about it, learn about the differences between get high and THC, you know, hemp and cannabis. I think, support it with your vote, if it came up in 
terms of something having to vote on, I think it should be voted positively, I think people could invest with their money, you know, they could invest with the cooperative, they could come up with ways to be supporting members of an organization that is also promoting the positive use of and the enhancement and growth of hemp, industrial, medical or whatever. So I think that's the real thing, for people to support, they have to understand what they aren't supporting - because a lot of people are opposed to THC marijuana and they are opposed to recreational - and there's a medical benefit to THC if used in the right dosage. So the question comes down to, is the street stuff or person growing their own thing, that's not what we're talking about. We're talking something that would be used in a more controlled, medical environment. There is a place for it. You know, it's not making candy out of THC and selling it to people who want to get it. That's a market, there is a market for that, but the industrial hemp market is not of that nature. So, I think the awareness needs to really come out clearly that hemp and growing industrial hemp really is not involved in that arena, unless you were growing CBD - the non-get high cannabinoid - which has a great medical benefit. So, you know, it helps you get off an opioid addiction. If you can get off an opioid addiction by taking a CBD hemp oil that has no THC in it whatsoever, and you're benefiting the person, why not? Mr. X. Well, we have lobbying days and stuff I have planned. I have to look back, but we have a day for industrial hemp at the capitol to show the different aspects, commodities, that can be produced, the benefits to the environment and economy. I think there's going to be some health food companies that will showcase their commodities whether health food, snack bars, hemp that people can mix in their cereal or yogurt, it's 
really a nice addition, give it a nutty flavor, smells a lot and tastes a lot like sunflower seeds.

Mr. Y. That's a really good question. I talked to somebody in my college if I could do a Kickstarter campaign and they were not supportive of that idea although I know it has been used in other states. One person could not fund one research program, but if I had 100 people willing to donate 100 dollars, that would cover seed costs and hire an undergrad to help me plant and so on. If a thousand people donated, well now we're talking about a couple of years I could have some real recommendations. If I can't get federal money or an organization started, I really don't know how long I can stay in this business.

Mr. Z. I would advise them to first and foremost to educate themselves. Secondly, those entering the industry I would advise to do so cautiously, I do not want to see them lose money on their endeavors. Thirdly, I would urge them to get politically involved, and call all their elected officials and demand the gold standard in all legislation and rules concerning all cannabis, medical, recreation, and industrial agricultural hemp. I would urge them to contact our federal officials too. Those are the three main things; educate yourself, be careful with your money, and get on the phone and start to demanding the best. This is a whale of an industry. I have private 90 some page report that shows who's who in the cannabis industry and one compelling message in the report is the phenomenal business opportunities we're facing. Something like this in these strange economic times cannot be disregarded. It is my opinion that it is inevitable so we need to get it done, done right, end this idiotic cannabis prohibition and get to work, there is a lot that can be done.

\section{Industrial Hemp as a Textile}


There are several end uses for industrial hemp. One of these is for use in textiles (cordage, rope, construction, clothing, etc.). What are your thoughts on using industrial hemp as a textile source?

Mr. W. Oh most definitely. I think the textile industry is a huge marketplace. I have a friend of mine who was in organic - she was the first organic cotton company in the United States - her company is called Maggie's Organics. I've known her for over 45 years, I remember when she started up her cotton cooperative, you know she started with organic cotton and it's the same kind of thing. I think hemp definitely has a place in textiles, in paper, in paper production, I think it could be used in construction materials, like hempcrete, mix it with concrete. There are ways automobile manufacturers are using hemp fiber in their molded door panels, you know, BMW $<$ Mercedes-Benz, Volvo, they're all using recyclable hemp products in their molding materials. Hemp on every level it can produce, there is nothing that needs thrown away from that plant whatsoever You can use every piece of the plant. And it enriches the soil. Any toxins you have in your soil the hemp can pull those toxins out. Farmers have been spraying poisons on their lands for years, so all those pesticides and toxins are in the soil, start growing industrial hemp, it can pull those out of the soil. Pretty cool.

Mr. X. Well, it's a very durable textile, I see it potentially in furniture, fabric coverings, couches, carpets, clothing, and draperies. It has unlimited potential. There is an antibacterial property to hemp, it seems to, wouldn't say it kills bacteria, but it has a capacity to resist bacteria.

Mr. Y. Again, as long as you have the infrastructure to convert that raw plant material into a fiber, it makes a lovely textile. We think of it as rope material, but it can be fine 
and soft, something you want to wear. it doesn't have to be hairy and itchy. I was reading a really interesting article, in France it is legal to grow, they don't have the legal restrictions that we do. There is a company there that makes fine paper from hemp, so there are all these potential niches, or craft, high value markets that are there if we can get over some of these hurdles.

Mr. Z. Industrial hemp as a textile source is going to be a whole new era in American textile production. Again, this is an industry that cannot be offshored easily. Other countries are already making hemp textiles and cannot meet the demand. The Italians have perfected the hemp linen textiles. The Chinese mass produce and are dominating the textile business at this time. In my humble opinion, it will revitalize, along with American bamboo, our domestic textile industry and that will, of course, revitalize American's garment industry. One thing I want to add, I told you the other day I had been in the garment industry, and I dearly love the Moto garment industry. I have seen enough motorcycle garments that are absolute junk that sure are pretty. You pay for what you get, the better quality, the higher the quality. I see a big potential for hemp in the motorcycle garment industry. 


\section{Appendix C}

\section{Experiences and Perceptions of West Virginia Stakeholder's Towards Industrial Hemp \\ Mind Map}

Directions: Given the central theme below (Industrial Hemp) there are six boxes indicating gix possible end uses for industrial hemp. With each end use designated, add at least four deacriptors (either above or below the appropriate box) you associate with this end use.

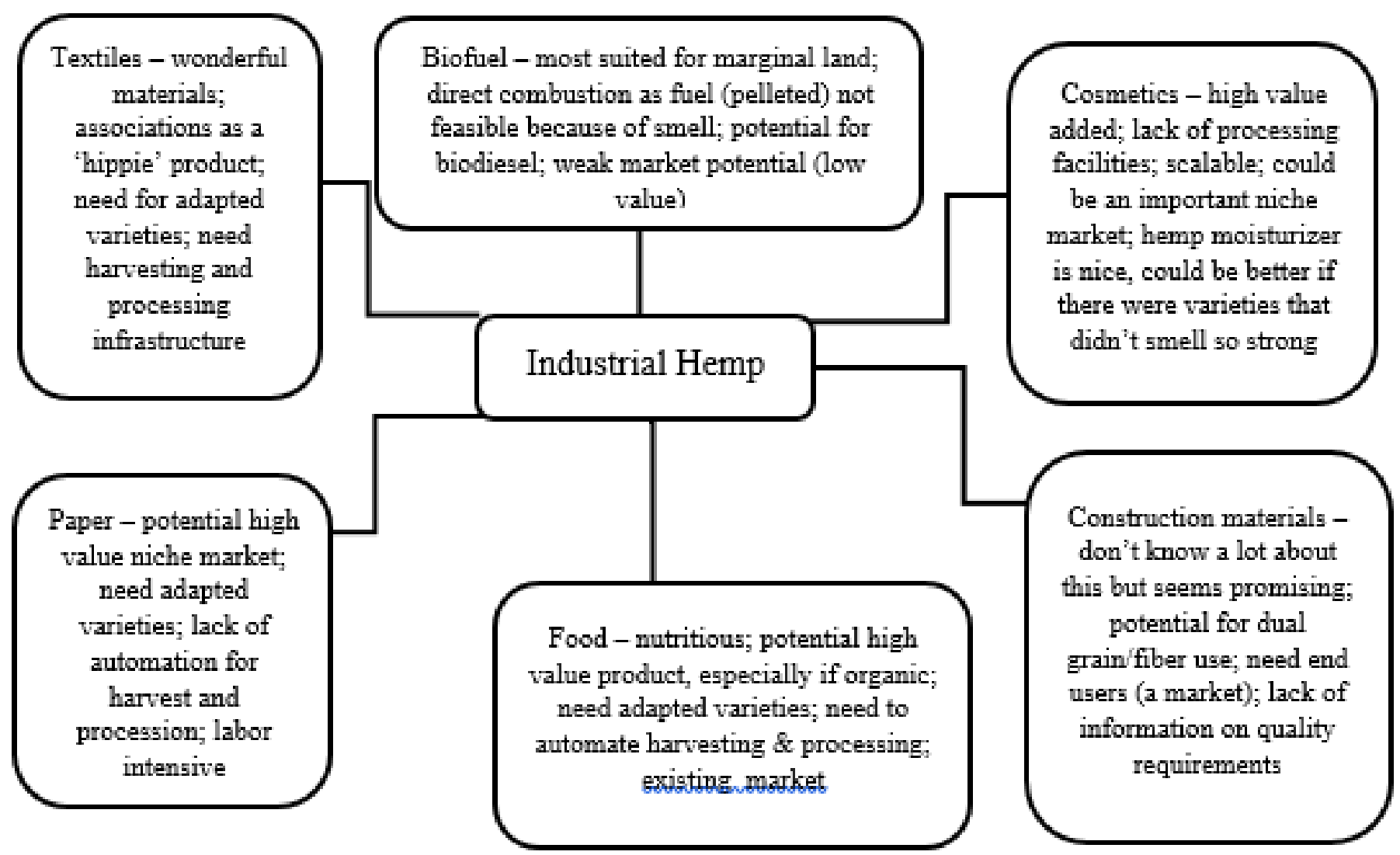

\section{Mind Map}

Mr. Y 


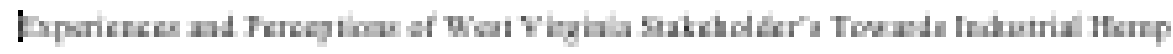

aind Mre

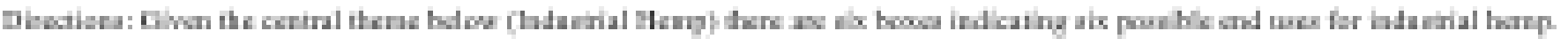

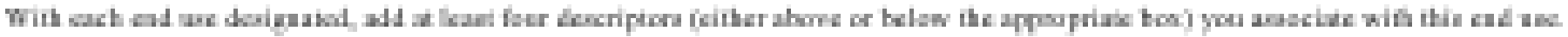

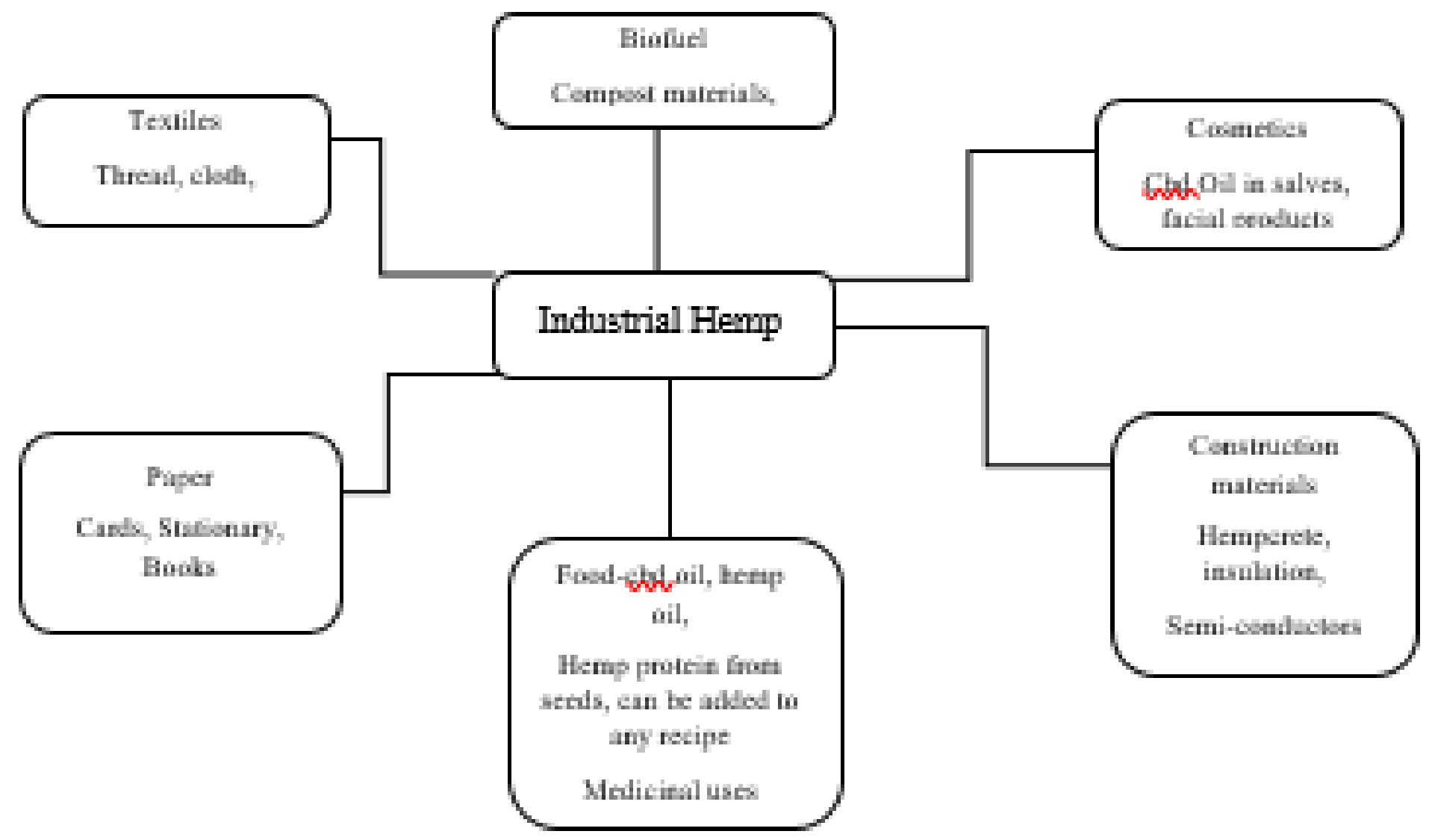

Mind Map

Mr. W 


\title{
Appendix D
}

\section{Research Protocol}

Interview Questions for Research on the Experiences and Perceptions of West Virginia Stakeholders on Industrial Hemp

\author{
Rebekah Stevenson
}

Directions: Participants may feel free to skip any questions they feel uncomfortable with answering. Within each question, the participant may add any more information they would like pertaining to that question and may take time at the end to add additional comments if they so choose.

\section{Knowledge Base}

- How did you first hear about industrial hemp?

- Tell me about what you know of industrial hemp's growth, processing, end uses, and challenges?

- Which of those stood out to you the most as being a key piece you wanted to know more about?

\section{Involvement and Support}

- Once you were interested in industrial hemp, how did you become involved?

- What can you tell us about the steps you took to pursue this area you are involved in? 
- Currently, what is your affiliation, role, or association with industrial hemp?

- What was the reaction from those around you when you expressed interested and became involved?

- What types of help and support have you found in the community of industrial hemp growers, politicians, and others?

- Tell me about your involvement with any of the known industrial hemp organizations in West Virginia?

\section{Future of Industrial Hemp in West Virginia}

- Where do you see industrial hemp going in the future within West Virginia?

- Where would you like to see industrial hemp go in West Virginia? What is your vision that you have for this crop in this state?

- Anything you would do over again or change about your experience with industrial hemp? Will you plan on continuing in the role you now take in industrial hemp?

- What would you advise those who are interested in supporting industrial hemp in West Virginia?

\section{Industrial Hemp as a Textile}

- There are several end uses for industrial hemp. One of these is for use in textiles (cordage, rope, construction, clothing, etc.). What are your thoughts on using industrial hemp as a textile source? 
Experiences and Perceptions of West Virginia Stakeholder's Towards Industrial Hemp

Mind Map

Directions: Given the central theme below (Industrial Hemp) there are six boxes indicating six possible end uses for industrial hemp. With each end use designated, add at least four descriptors (either above or below the appropriate box) you associate with this end use.

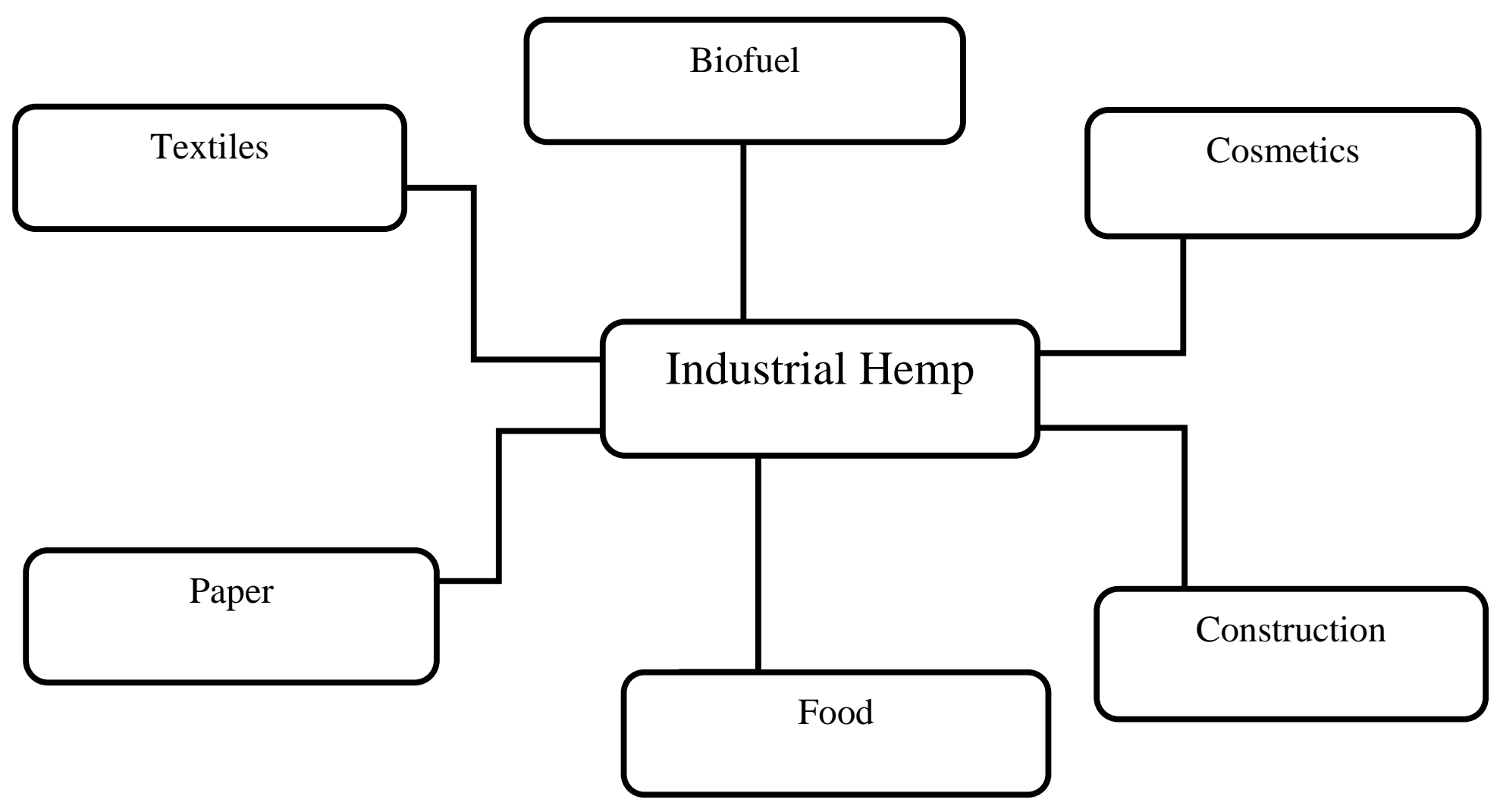




\section{WestVurginiaUniversity. \\ Office of Research Integrity and Compliance \\ 886 CHESNUT RIDGE ROAD MORGANTOWN, WV 26506}

\section{Acknowledgement Letter Exempt Initial Protocol Review \\ Action Date 10/13/2016 \\ To Kathryn Jones \\ From WVU Office of Research Integrity and Compliance \\ Approval Date 10/13/2016 \\ Expiration Date 10/12/2019 \\ Subject Acknowledgement Letter Exempt Initial Protocol Review \\ Protocol Number 1609297023}

Title Experiences and Perceptions of West Virginia Stakeholders on Industrial Hemp

The above-referenced study was reviewed by the West Virginia University Institutional Review Board IRB and

was granted exemption in accordance with 45 CFR 46.101.

- This research study was granted an exemption because the Research involves educational tests, survey procedures, interview procedures or observation of public behavior and (i) information obtained is recorded in such a manner that human subjects cannot be identified, directly or through identifiers linked to the subjects; and (ii) any disclosure of the human subjects responses outside the research could not reasonably place the subjects at risk of criminal or civil liability or be damaging to the subjects financial standing, employability, or reputation [45 CFR 46.101(2)]. All exemptions are only good for three years. If this research extends more than three years beyond the approved date, then the researcher will have to request another exemption. The following documents have been acknowledged for use in this study and are available in the WVU+kc system:

Documents reviewed and/or approved as part of this submission:

Cover Letter.pdf: 2016-10-06-04:00

Mind Map.docx: 2016-10-06-04:00

Interview questions.docx: 2016-10-06-04:00

Cover Letter.docx: 2016-09-30-04:00

Mind Map.docx: 2016-09-30-04:00

Interview questions.docx: 2016-09-30-04:00

Documents for use in this study have been acknowledged and are available in the WVUkc system in the Notes

and Attachments section of your protocol.

The Office of Research Integrity and Compliance is here to provide assistance to you from the initial submission

of an IRB protocol and all subsequent activity. Please feel free to contact us by phone at 304.293.7073

with any

question you may have. Thank you.

WVU Office of Research Integrity and Compliance

Date:10/13/2016

Signed:

Johnathan M. Herczyk

IRB Administrator 


\section{WestVirginiaUniversity.}

DAVIS COLLEGE OF AGRICULTURE, NATURAL RESOURCES AND DESIGN

Dear Participant,

This letter is a request for you to take part in a research project to explore the experiences and perceptions that stakeholders in West Virginia hold about industrial hemp. The purpose of this study is to explore that experiences and perceptions in order to gain information on how industrial hemp is being perceived by West Virginia stakeholders. This project is being conducted by Rebekah Stevenson, BA in the Davis College of Agriculture, Natural Resources and Design at WVU under the supervision of Dr. Katie Jones, an assistant professor in the School of Design and Community Development. This study is research in partial fulfillment for a Master's Degree in Design and Merchandising. Your participation in this project is greatly appreciated and will take approximately 30-45 minutes to answer the interview questions and accompanying material.

Your involvement in this project will be kept as confidential as legally possible. The interviews will be audio recorded and all tapes will be destroyed following their transcription. You must be 18 years of age or older to participate. Your participation is completely voluntary and you may skip any question that you do not wish to answer and discontinue at any time. This will in no way affect your class standing, grades, or job if you choose to discontinue the study. West Virginia University's Institutional Review Board has reviewed this study and it is on file.

I hope that you will participate in this research project in understanding West Virginia stake holder's perceptions and experiences with industrial hemp. Thank you very much for your time. Should you have any questions about this letter or the research project, please feel free to contact Rebekah Stevenson at (681) 443-1305 or by e-mail at rkwatson@mix.wvu.edu or Dr. Katie Jones at (304) 293-6735 or at kathryn.jones@mail.wvu.edu.

Thank you for your time and help with this project.

Sincerely,

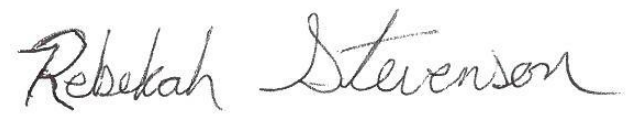

Rebekah Stevenson 